\title{
An analytical study of the atmospheric boundary layer flow and divergence over a SST front
}

\author{
Ayet Alex ${ }^{1,2,{ }^{*}}$, Redelsperger Jean-Luc ${ }^{3}$
}

1 Ifremer, CNRS, IRD, UBO/ Laboratoire d'Océanographie Physique et Spatiale (LOPS), IUEM Brest

France

2 LMD/IPSL, CNRS, École Normale SupérieurePSL Research University Paris France

${ }^{3}$ CNRS, Ifremer, IRD, UBO / Laboratoire d'Océanographie Physique et Spatiale (LOPS), IUEM Brest

France

*Corresponding author : Alex Ayet, email address : alex.ayet@normalesup.org

\begin{abstract}
:
We present an analytical model reproducing literature-based numerical simulations of the Marine Atmospheric Boundary Layer (MABL) over a SST front, with wind blowing from the cold to the warm side. Turbulence is parameterised through a varying diffusion coefficient with two critical features: it is parabolic on the vertical and its mean value is decoupled from the MABL height (unlike an Ekman layer model). These two novel features are found essential to recover the internal structure of the MABL from numerical simulations. Different dynamical regimes are obtained and interpreted in terms of non-dimensional numbers characterising the relative importance of terms driving the momentum equation. A closed-form expression of the vertically integrated wind divergence in the MABL is then obtained. The resulting divergence is linearly linked to the SST Laplacian and to the downwind SST gradient. This shows that the response of the MABL wind divergence to a SST front is highly dependent on its spatial scale. The coupling coefficients vary with the ratio of MABL height to turbulence strength, i.e. the inverse Ekman number. We further show different regimes in the rate of variation of the coupling coefficients, depending on the Ekman number value. This can result in qualitatively different vertical winds, having potential implications for the coupling of the MABL with the free troposphere.
\end{abstract}

Keywords : air-sea interaction, SST front, boundary layer flow, analytical model 


\section{Introduction}

Air-sea interactions over sea surface temperature (SST) fronts have aroused renewed interest in recent years (see the reviews Xie 2004; Small et al. 2008). Observations of the marine atmospheric boundary layer (MABL) structure, surface winds and wind stress over SST fronts show persistent patterns, on monthly time scales and on spatial scales from 50 to $100 \mathrm{~km} \mathrm{(e.g.} \mathrm{Businger} \mathrm{and} \mathrm{Shaw} \mathrm{1984;} \mathrm{Liu}$ et al. 2000; Chelton et al. 2004, 2007; Chelton and Xie 2010; O'Neill et al. 2003, 2005), with stronger surface wind stress and speed $r$ the warm part of the front. These imprints and associated horizontal wind divergences have been shown to have important impacts on the free troposphere dynamics (e.g Foussard et al. 2018).

Two main physical mechanisms are put forth in the literature to explain the generation of ageostrophic wind in the MABL: the uownward momentum mixing mechanism (Wallace et al. 1989; Hayes et al. 1989) and the pressure adjustment mechanism (Lindzen and Nigam 1987). In the former, the wind increase is explained by a change in vertical momentum mixing and boundary layer thickness, 1 (3)

Induced by a destabilisation of the MABL on the warm side of the front. It results (O'Neill et al. 2003; Chelton et al. 2004) in a linear respondence between the divergence of the wind stress perturbation and the downwind SST gradient field. In the latter, the SST dient drives an atmospheric pressure gradient. The consequence is a linear relation between the horizontal divergence of the wind and the Laplacian of SST, and thus the vertical wind speed in the MABL. This link has been studied numerically in idealized (Spall 20)7; Kilpatrick et al. 2014) and more realistic (Lambaerts et al. 2013; ONeill et al. 2017; Plougonven et al. 2018; Foussard et al. 2019) configurations, along with its consequences on the full troposphere (e.g. Minobe et al. 2008; Takatama et al. 2012, 2015).

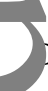
ifferent aspects of the MABL response to an SST front have been investigated using analytical models. The MABL-height wriation as a consequence of an atmospheric temperature difference has been derived in Hsu (1984) and Hsu et al. (1985), using nermodynamical model. Within the same line of work, Laikhtman and Yordanov (1979); Brown and Liu (1982); Kudryavtsev (1996) used on deriving both the MABL height and the turbulent intensity variations by using a two layer model, with an Ekman layer on of a bottom surface log-layer. The relative contributions of downward momentum mixing and pressure adjustment mechanisms to eration of ageostrophic wind have been studied in Bourras et al. (2004) with a simple linear wind stress parameterisation in the M IBL. Other works have focused on the downward momentum mixing mechanism by assuming a sharp front (Samelson et al. 2006) or on the pressure adjustment mechanism to study the impact of the MABL wind divergence on the free troposphere above with an E' nan layer model (Feliks et al. 2004). A semi-analytical model (Schneider and Qiu 2015) has also been developed to investigate the response of the MABL to an undulating SST front. The linear reduced-gravity model includes both coupling mechanisms and a non nstant vertical turbulent diffusion. Coupling between wind stress divergence and downwind SST gradients was found be sensitive to turbulent diffusion representation.

Focusing on the case of a wind blowing from the cold to the warm side of the front, several numerical investigations of the MABL structure have been performed (Spall 2007; Kilpatrick et al. 2014). Results show a complex vertical structure of the wind in the MABL, questioning to what extent it can be reproduced by a simple model of the type Schneider and Qiu (2015), and how it affects the horizontal wind divergence within the MABL. In particular, numerical simulations reveal that (i) the vertical profile of the turbulent diffusion coefficient (driving the vertical momentum mixing) in the MABL is not horizontally and vertically constant, and has a parabolic vertical shape; (ii) more importantly, the relationship between the intensity of the turbulent diffusion coefficient and the MABL height as prescribed in standard Ekman layer theory is not satisfied. In the present work, we present an analytical model including those two features, to investigate the vertical and horizontal structure of the MABL and the resulting mean wind divergence

The analytical model is presented in Section 2. It includes both above-mentioned features, which allows exploration of different dynamical regimes of the MABL response to an SST front. These are characterised by means of dimensionless parameters in Section Ihis article is protected by copyright. Afl rights reserved. 
3. The model is then compared to a state-of-the-art idealized numerical simulation (Section 4). A closed form for the verticallyintegrated horizontal wind divergence is then derived from the model in Section 5. It links the physical processes responsible for the internal dynamical structure of the MABL to the response of the vertically-integrated divergence to different features of the SST field. Conclusions are presented in Section 6.

\section{Analytical model description}

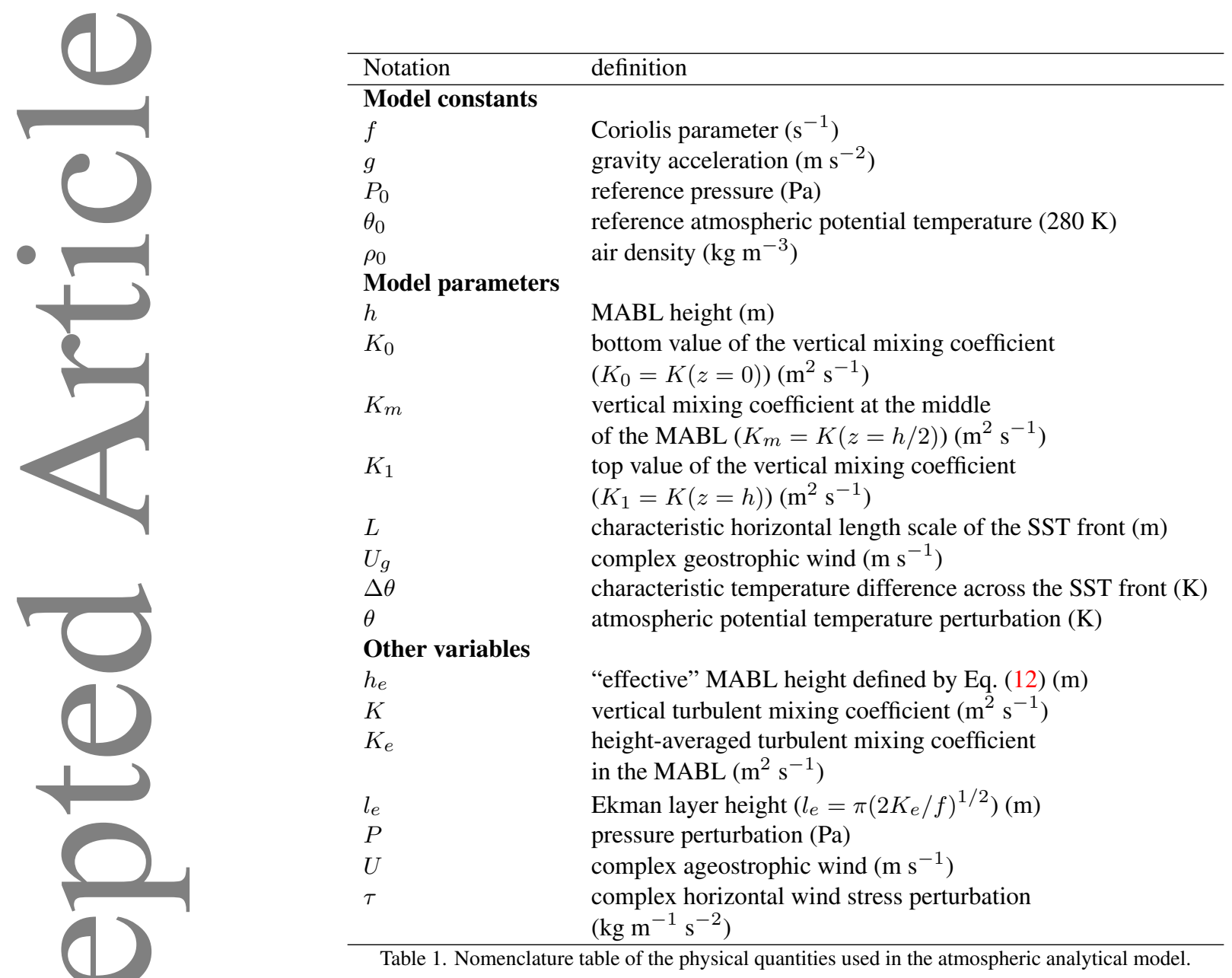

In this section, we describe the quasi-equilibrium response of the MABL to an SST front within an analytical framework, reproducing re ilts from numerical simulations. The analytical model setup is summarised in Figure 1 with notations given in Table 1. A crossfront zonal geostrophic wind $U_{g}$ is considered, blowing from the cold to the warm part of the front. The cross-front (zonal), along-front (meridional) and vertical coordinates are denoted by $x, y$ and $z$ respectively. In order to derive the ageostrophic wind in the MABL,

model uses the momentum balance. The thermodynamical and turbulent structure are model parameters unlike other works where they were determined from a heat balance or Monin-Obukhov theory (e.g. Hsu 1984; Brown and Liu 1982; Kudryavtsev 1996).

In addition to the quasi-equilibrium assumption (i.e. $\partial_{t}(\cdot)=0$ ), cases with low Rossby number (denoted Ro) are considered, so that momentum advection can also be neglected. By denoting $U=u+i v$ the complex ageostrophic wind generated in the MABL, $L$ the characteristic horizontal length scale of the SST front and $f$ the Coriolis parameter $\left(\sim 10^{-4}\right.$ in the following), this assumption reads

$$
\operatorname{Ro}=\frac{\left|U+U_{g}\right|}{f L} \ll 1
$$

The horizontal momentum balance, on an f-plane, is obtained by expanding around a reference vertically uniform MABL characterised by an hydrostatic pressure $P_{0}$ in geostrophic equilibrium with $U_{g}$ and a constant potential temperature $\theta_{0}$ (equal to $280 \mathrm{~K}$ in the This article is protected by copyright. Afl rights reserved. 
following). It reads

$$
\underbrace{\frac{1}{\rho_{0}} \partial_{z} \tau}_{\text {turbulent mixing }} \underbrace{-i f U}_{\text {Coriolis force }}=\underbrace{\frac{1}{\rho_{0}}\left(\partial_{x} P+i \partial_{y} P\right)}_{\text {pressure force }}
$$

where $\theta$ and $P$ are the potential temperature and pressure perturbations, and $\tau$ the complex wind stress perturbation. The momentum equation is an Ekman-like balance, as defined in Samelson et al. (2006); Spall (2007); Kilpatrick et al. (2014). It describes the MABL in the regions where it is nearly at equilibrium with SST. By further assuming a hydrostatic atmosphere, i.e. under the condition that

$$
\left|\frac{c_{v}}{c_{p}} \frac{P}{P_{0}}\right| \ll\left|\frac{\theta}{\theta_{0}}\right| \ll 1
$$

vertical momentum balance for the perturbations reads

$$
\frac{1}{\rho_{0}} \partial_{z} P=g \frac{\theta}{\theta_{0}}
$$

where $c_{v}$ and $c_{p}$ are the isobaric and isochoric heat capacities of dry air. Note that relaxation of condition (1) would require the use of a numerical scheme to solve the momentum balance (e.g. Schneider and Qiu 2015, where the first order non-linear advection term is considered).

The analytical model relies on four assumptions, based on results from numerical simulations both from the literature (Spall 2007; Nilpatrick et al. 2014) and performed in the present work (see Section 4). First, the MABL is assumed to be well mixed, which implies th atmospheric potential temperature is constant on the vertical. The horizontal momentum balance can thus be rewritten as

$$
\frac{1}{\rho_{0}} \partial_{z} \tau-i f U=\frac{g}{\theta_{0}}\left[(z-h)\left(\partial_{x} \theta+i \partial_{y} \theta\right)-\left(\partial_{x} h+i \partial_{y} h\right) \theta\right]
$$

where the pressure perturbation has been computed by vertically integrating the vertical momentum equation (Eq (4)) from the top of MABL $h$ to a given height $z$.

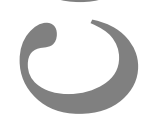

Second, we assume that the ageostrophic wind is zero at the top of the MABL (simulations show a weak ageostrophic wind). We ther assume a no-slip surface condition, leading to the following boundary conditions:

$$
U(x, y, h)=0 \text { and } U(x, y, 0)=-U_{g}
$$

Third, the stress vector is classically related to the wind shear through a turbulent mixing coefficient $K$

$$
\tau(x, y, z)=\rho_{0} K(x, y, z) \partial_{z} U(x, y, z)
$$

and, following numerical simulations (e.g. Kilpatrick et al. 2014), we assume the coefficient to be parabolic along the vertical

$$
\left.\left.\begin{array}{c}
K(x, y, z)=A(x, y)+B(x, y) \\
\text { This article is protected by copyright. All rights reserved. }
\end{array}\right]+\frac{h(x, y)}{2}\right]^{2}
$$


For clarity, the parabola is defined through the mixing coefficient values at the bottom $\left(K_{0}\right)$, middle $\left(K_{m}\right)$, and top $\left(K_{1}\right)$ of the MABL, i.e. such that

$$
\left\{\begin{array}{l}
A(x, y)=K_{m}(x, y) \\
B(x, y)=\frac{K_{1}(x, y)-K_{0}(x, y)}{h(x, y)} \\
C(x, y)=\frac{2\left[K_{0}(x, y)+K_{1}(x, y)-2 K_{m}(x, y)\right]}{h^{2}(x, y)}
\end{array}\right.
$$

4 Neglecting advection implies that the model solves the momentum balance in independent vertical columns, labelled by the horizontal coordinate $(x, y)$. Using the first three assumptions, the dynamical structure (i.e. the wind $U$ ) of each column is uniquely defined in the model by prescribing $\theta, \partial x, y \theta, h, \partial_{x, y} h$ and $K$.

The last assumption, on the thermodynamical structure of the independent columns, is twofold. First, the horizontal variations of ential temperature are assumed to follow SST variations with an horizontal lag that destabilises the MABL (as drawn in Figure 1). Tr s was found in previous numerical simulations for flows over realistic (Lambaerts et al. 2013) and idealized (Kilpatrick et al. 2014) SST fields. Second we consider that the intensity of the turbulent diffusion coefficient (i.e. $K_{0}, K_{1}$ and $K_{m}$ ) and the MABL height (h) are proportional to potential temperature (and thus SST perturbation with some lag). This relationship holds assuming to be in the thermal wake of the SST front, where the atmosphere is not in local thermal equilibrium with the ocean, and the turbulent structure thus mainly determined by the air-sea temperature difference. Since the MABL is invariant along the along-front direction ( $y$ ), this implies that in the above equations, potential temperature can be used as the cross-front coordinate, i.e. we replace $(x, y)$ by $\theta$ in the vious equations. In particular, replacing $h(x, y)$ by $h(\theta)$ in the momentum balance (5) yields

$$
\frac{1}{\rho_{0}} \partial_{z} \tau-i f U=\frac{g}{\theta_{0}}\left[z-h(\theta)-\theta \partial_{\theta} h\right]\left(\partial_{x} \theta+i \partial_{y} \theta\right)
$$

1

Note that this change of variables does not imply that $U$ depends solely on $\theta$, since it also depends also on its horizontal gradient.The hoi izontal lag in potential temperature with respect to SST impacts both MABL height and turbulent intensity. It accounts to some extent for non-linear advection affecting both fields. This lag is calibrated from numerical simulations (see Section 4).

The simplicity of the model allows for an analytical solution to be found (see Appendix A for details). This is used in the next se tions to both perform an in-depth analysis of the solution properties and to derive an exact expression of the wind-divergence within MABL. Equation (10) is solved using the Legendre functions, a generalization of the Legendre polynomials, for non integer order an degree. The solutions reveal that assuming a parabolic turbulent mixing coefficient (i.e. $\partial_{z} \tau \neq 0$ in Eq. (10)) has a large impact on the solution and thus the MABL structure. Section 5 further shows that this difference results in a qualitatively different response of the vertically-integrated wind divergence.

\section{Internal dynamical structure of the MABL}

To characterise the behaviour of the analytical model solutions, the following non-dimensional numbers are defined to quantify the relative importance of the mixing, pressure and Coriolis terms in the momentum balance (10)

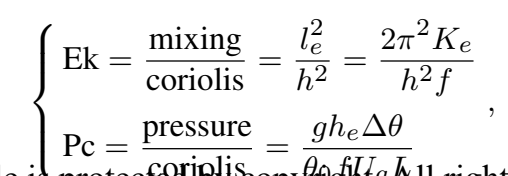

This article is protecfediblis copyfight 9 All rights reserved. 
(a)

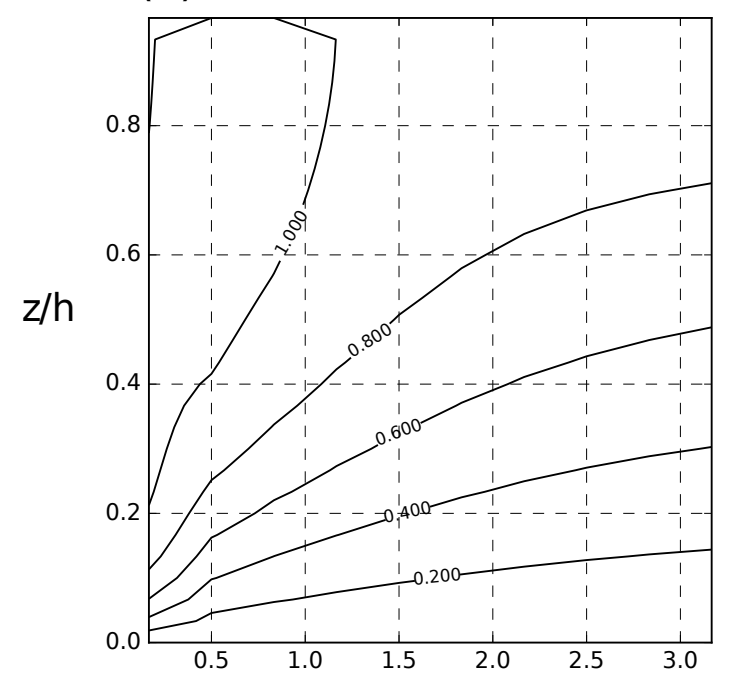

(b)

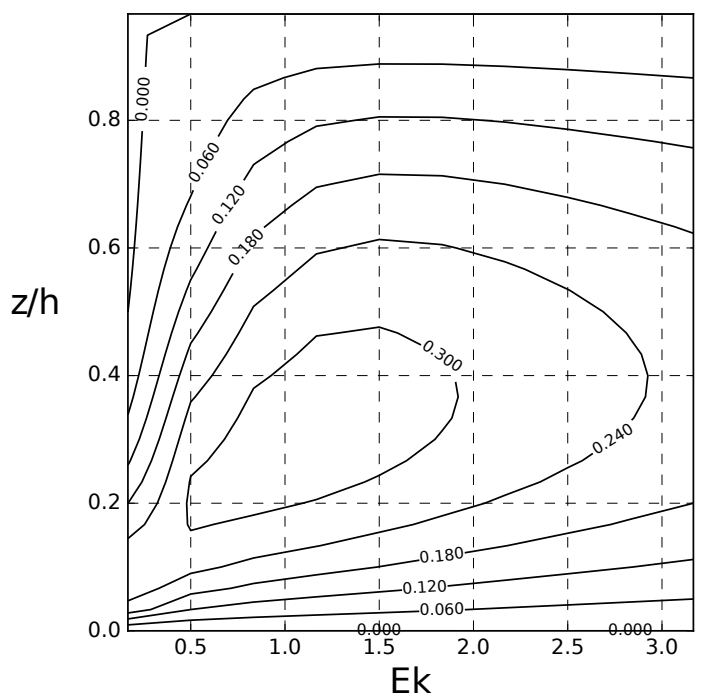

Ek (c)

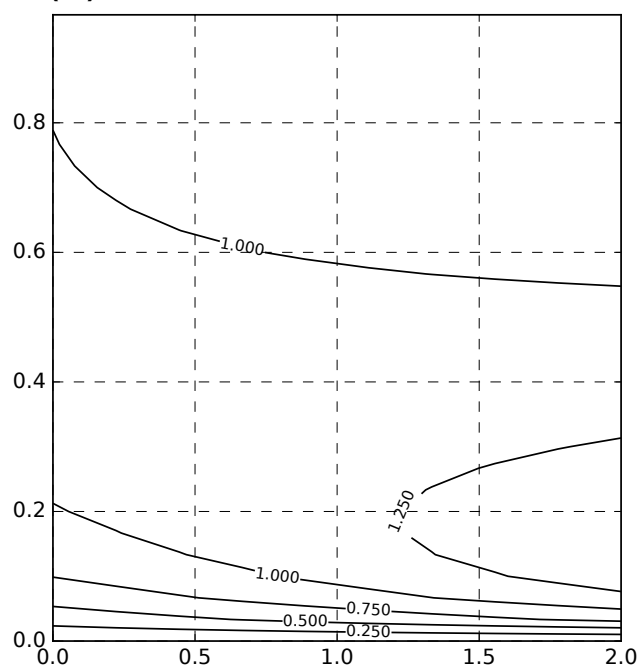

(d)

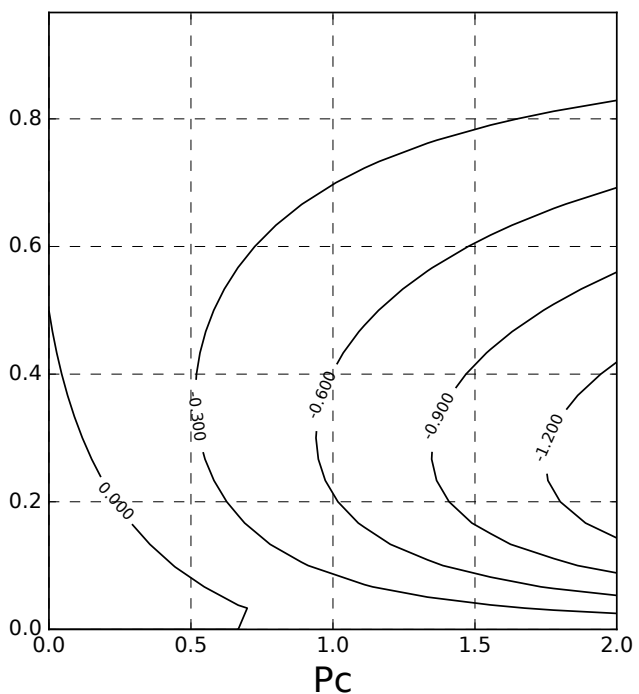

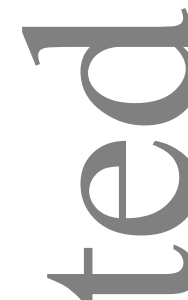

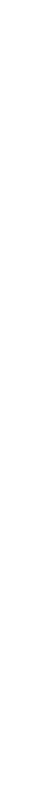

Figure 2, Zonal (a and c) and meridional (b and d) relative wind $U / U_{g}$ as a function of height for different regimes: (a) and (b) for Pc $=0$ as a function of Ek; (c) and (d) fo $\mathrm{Ek}=1$ as a function of $\mathrm{Pc}$

th $\mathrm{s}$ interpreted as a free parameter reflecting how the MABL adjusts to a SST perturbation. Its variation accounts for changes in environmental conditions (e.g. the upwind MABL structure)

Non-dimensional vertical wind profiles as a function of Ekman number are presented on Figures $2 \mathrm{a}$ and $2 \mathrm{~b}$. The pressure gradient is to zero and variation of the Ekman number is achieved by varying the three values parameterizing the mixing coefficient ( $K_{0}, K_{1}$ and $K_{m}$ ) uniformly, with $K$ nearly constant on the vertical (i.e. $K_{0}=K_{1}=K_{m}-0.1 \mathrm{~m}^{2} \mathrm{~s}^{-1}$ ).

For Ek $\sim 1$, a vertical wind profile close to that of an Ekman layer is obtained, i.e an Ekman spiral with a supergeostrophic region starting at $z \sim 0.8 h$, also called upper layer jet (e.g. Samelson et al. 2006). The difference with a standard Ekman layer is here mostly that the top boundary condition is set at a finite height $h$.

As mentioned above, allowing for values of Ek different than 1 is a specificity of the analytical model (in contrast to Feliks $e t$ al. 2004, where it is set to 1). For values of Ek larger than one, the wind becomes more homogeneous in the MABL as the Ekman layer extends upwards. For values less than 1 , the wind shear increases close to the ground and the upper layer jet extends deeper near the surface, e.g. starting at $z \sim 0.4 h$ for $\mathrm{Ek}=0.5$.

Figure 2a also reveals that the sensitivity of the zonal wind to variations in Ek decreases as Ek increases. This has important implications for the vertically-integrated wind divergence, as discussed in Section .5. 
Variation of the Ekman number has also been performed by varying only $K_{m}$ keeping $K_{0}$ and $K_{1}$ fixed (i.e. increasing the curvature of the horizontal parabola followed by $K$, not shown here). In this case, an increase of the Ekman number decreases the shear in the middle of the boundary layer, but a similar shear as previously is obtained close to the top and bottom boundaries.

\subsection{Role of the pressure gradient}

For a fixed temperature difference $\Delta \theta$ and geostrophic wind $U_{g}$, the Pc non-dimensional number varies as $h_{e} / L$ (with $L$ the typical dth of the SST front). It can thus be interpreted as either measuring the relative impact of pressure on the momentum balance (i.e. as ined in (11)), either as the inverse relative scale of the SST front.

When mixing vanishes $(\mathrm{Ek}=0)$, the momentum balance $(10)$ reduces to a geostrophic balance. In the analytical model, this is nivestigated by taking the limit $\mathrm{Ek} \ll 1$ with $\mathrm{Pc} \sim 1$ ( $\mathrm{Ek}=0$ would change the order of the momentum equation, hence the solution). The bottom boundary condition $(U=0)$ is incompatible with a purely geostrophic and vertically homogeneous equilibrium. The curbulent mixing term thus acts in a shallow bottom boundary sub-layer to create necessary vertical wind shear. This can be described thematically following a standard matched asympotics approach. If we let $\xi=z^{\prime} / \mathrm{Ek}^{1 / 2}$ in (14), we obtain

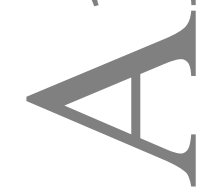

$$
\partial_{\xi}\left(K^{\prime} \partial_{\xi} U^{\prime}\right)-i U^{\prime}=\left(\mathrm{Ek}^{1 / 2} \xi-1\right)\left(\partial_{x^{\prime}}+i \partial_{y^{\prime}}\right) \theta^{\prime}
$$

which describes a MABL at geostrophic equilibrium, with a shallow sheared sub-layer at the ground (this equation is similar to the one de rived in Munk 1950, for an ocean basin wind-driven circulation with a western boundary current).

Figures $2 \mathrm{c}$ and $2 \mathrm{~d}$ show the influence of a variation of the pressure gradient on the vertical wind structure with Ek $=1$ (i.e. with re pect to a reference Ekman layer, recovered for $\mathrm{Pc}=0$ ). Consistently with the above matched asymptotics analysis, the Ekman layer be omes shallower with increasing pressure or decreasing front scale (for Pc $=1$, it starts at $z \sim 0.6 h$ ), with vertical zonal wind shear onfined to the bottom of the MABL.

For stronger values of Pc, negative meridional winds are observed, jointly with supergeostrophic zonal winds (i.e. at a height $~ 0.2 h$ for $\mathrm{Pc}=1.5$ ). This is interpreted as the geostrophic wind (negative meridional wind in the northern hemisphere) overcoming background Ekman wind. Note however that when Pc increases, the scale of the front decreases, which implies that advection might st $t$ playing a role in the momentum balance (thus invalidating the model assumptions).

\section{Comparison with a numerical simulation}

his section, we present a comparison of the analytical model with a numerical simulation to gain insight on the dynamical regimes revealed by the analytical model and to validate the assumptions presented in Section 2.

\subsection{Numerical model setup}

A typical configuration as encountered in the literature (e.g Spall 2007; Kilpatrick et al. 2014) is used with an SST anomaly of the form

$$
T(x)=\frac{\Delta \theta}{2}\left[1+\tanh \left(\frac{x-x_{0}}{L}\right)\right]
$$

with $L=100 \mathrm{~km}, x_{0}=1800 \mathrm{~km}$ and $\Delta \theta=3 \mathrm{~K}$. A background zonal geostrophic wind is prescribed with a value of $5 \mathrm{~m} \mathrm{~s}{ }^{-1}$ and balanced by a barotropic meridional pressure gradient. In this configuration, hypothesis (1) used in the analytical model is satisfied (with Ro $\sim 10^{-1}$ ). 
(a)

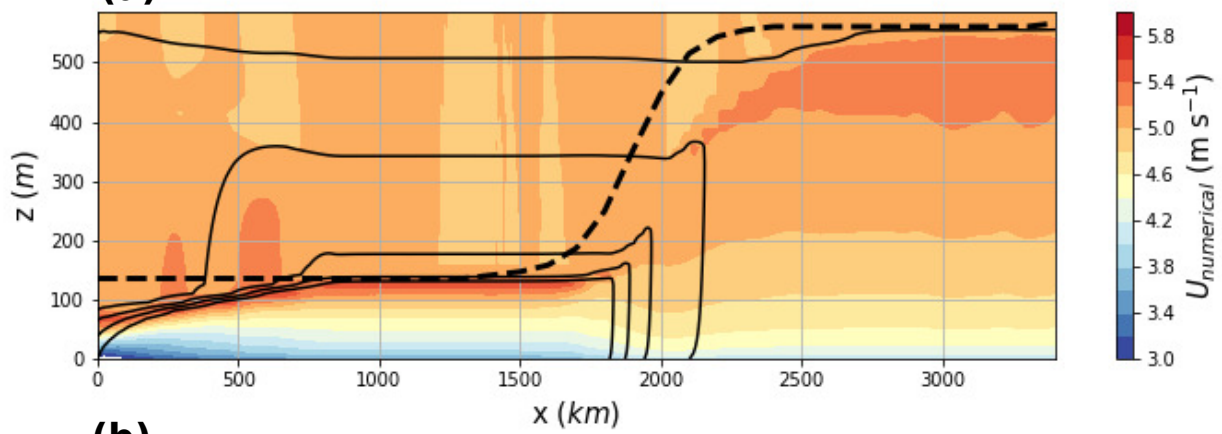

(b)

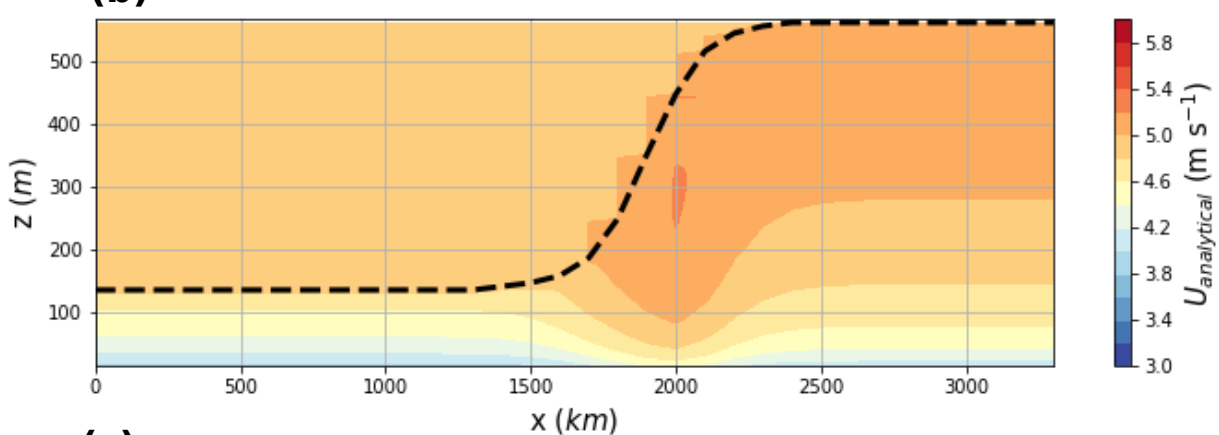

(c)

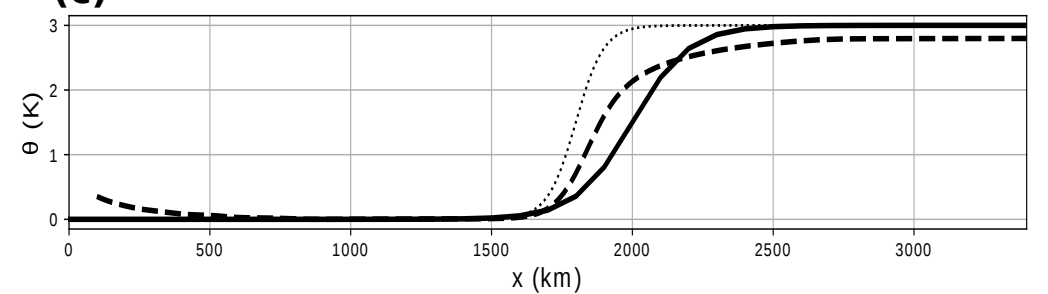

(1)

ure 3. Total zonal wind in $\mathrm{m} \mathrm{s}^{-1}$ (a) as simulated after 36 hours from the numerical model and (b) from the analytical solution; (c) SST (dotted line) and mean potential temperature (dashed line) from the numerical model, and extrapolated potential temperature used in the analytical calculations (solid line). Black contours in re potential temperature contours, with a difference of $0.5 \mathrm{~K}$ between two contours. Dashed line in (a) (b) is the extrapolated MABL height used in the analytical calculations.

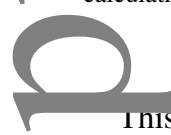

In1s configuration corresponds to large scale and weak fronts, as can be generated by large scale oceanic currents such as the Gulf St cam (e.g. Piazza et al. 2016), the Kuroshio Extension (Kawai et al. 2014), the Agulhas Current (e.g. Perlin et al. 2014) or associated with the Pacific Equatorial Cold Tongue (e.g. Anderson 2001).

The Mesoscale Non Hydrostatic model (Meso-NH) version 5.3.0 (Lafore et al. 1998; Lac et al. 2018) is used in its idealized twodi hensional configuration. Clouds, precipitation, and radiative fluxes are not considered. Open boundary conditions are prescribed along the $x$ direction. The domain dimensions are $3600 \mathrm{~km}$ in zonal direction and $20 \mathrm{~km}$ in the vertical. The horizontal resolution is $1 \mathrm{~km}$ whereas the vertical grid spacing varies from $1 \mathrm{~m}$ at the surface to $1000 \mathrm{~m}$ at $8 \mathrm{~km}$ height. We use an $f$-plane geometry with $f=10^{-4} \mathrm{~s}^{-1}$. In the troposphere a lapse rate of $6.8 \mathrm{~K} \mathrm{~km}^{-1}$ is prescribed with the tropopause at $12 \mathrm{~km}$. The turbulence scheme (Cuxart et al. 2000) is based on a 1.5-order closure and used in its one-dimensional form with the mixing length parameterized according to Bougeault and Lacarrere (1989). Sea surface fluxes are computed using the bulk parameterisation COARE3.0 (Fairall et al. 2003). The model starts from initial homogeneous geostrophic conditions, and runs for 36 hours. At this time, the flow is in a quasi-equilibrium state, even though the MABL continues to grow slightly and some inertial oscillations of the wind are observed above it.

\subsection{Analytical model setup and hypothesis}

In the following we discuss how the assumptions made in the derivation of the analytical model (Section 2) compare with the numerical simulation, and we calibrate the free parameters of the analytical model.(i.e. $\theta_{1} K_{0}, K_{1}, K_{m}$ and $\left.h\right)$. 


\section{(a)}

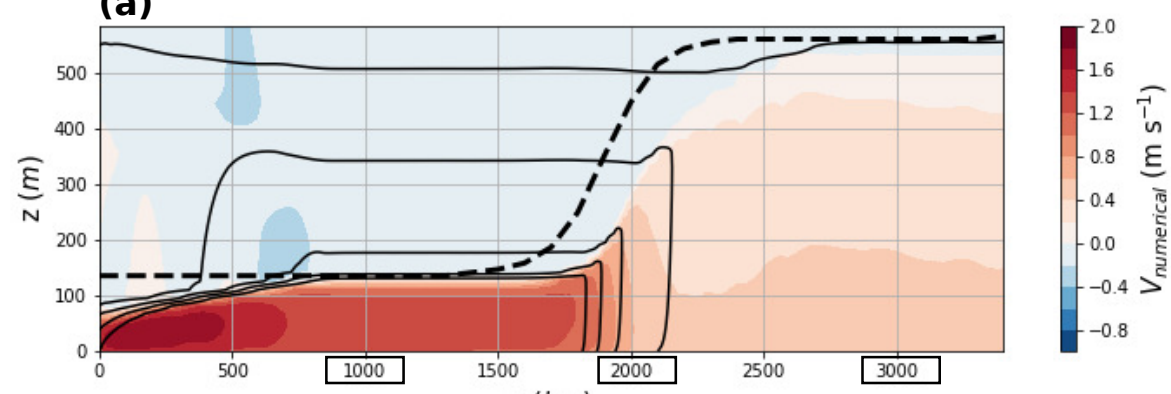

(b)

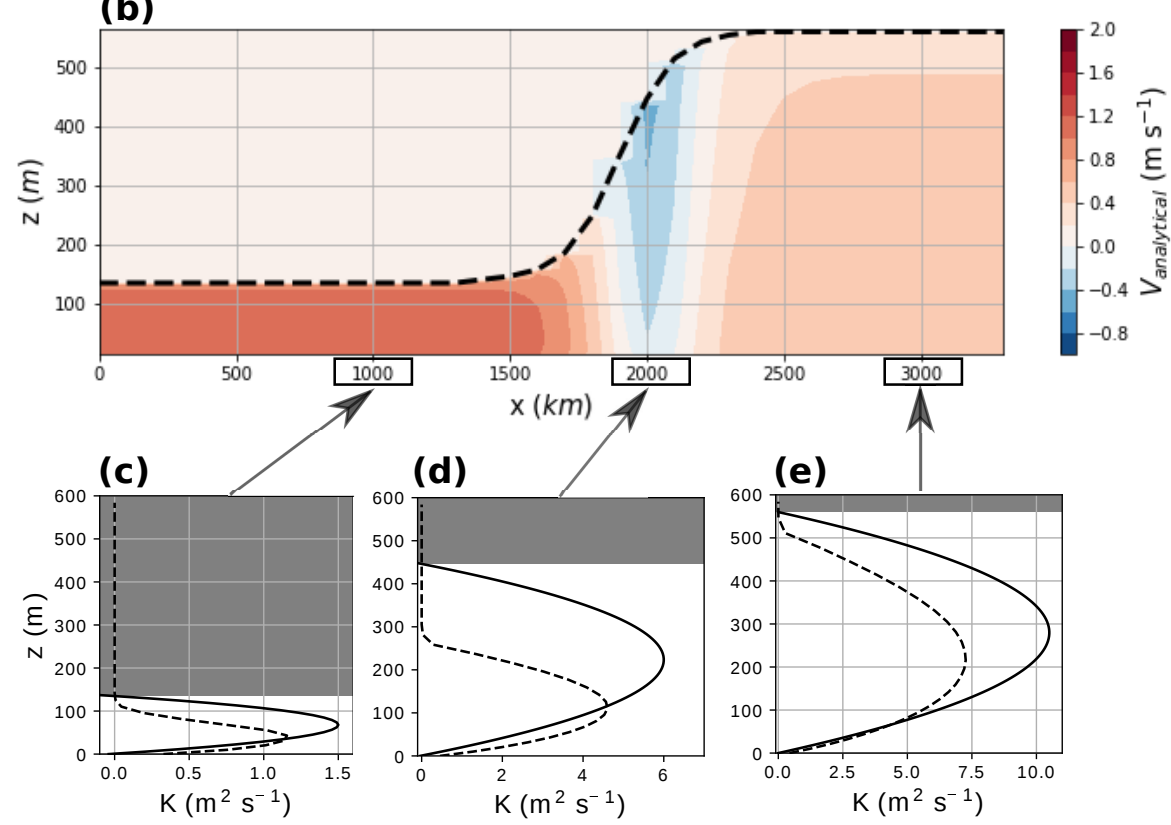

(1)

Figure 4. Total meridional wind in $\mathrm{m} \mathrm{s}^{-1}$ (a) as simulated after 36 hours from the numerical model and (b) from the analytical solution; (c) turbulent mixing coefficient puted from the numerical model. Black contours in (a) are potential temperature contours, with a difference of $0.5 \mathrm{~K}$ between two contours. Dashed line in (a) (b) is the extrapolated MABL height used in the analytical calculations. [(c), (d), (e)] Vertical profiles of the turbulent mixing coefficient used the analytical solution (solide line) nd as simulated from the numerical model (dashed line) (c) before, (d) above and (e) after the SST front.

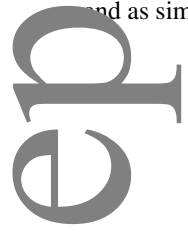

The total zonal and meridional winds from the numerical simulation are shown in Figures $3 \mathrm{a}$ and $4 \mathrm{a}$ (i.e. the sum of the ageostrophic $\mathcal{I}$ and the geostrophic wind $U_{g}$ ), together with the simulated potential temperature. The results show a bottom atmospheric boundary er, where potential temperature is vertically homogeneous, and on top of which the total wind matches the geostrophic wind. The ght of this layer increases with the cross-frontal coordinate. We define the MABL as this bottom atmospheric boundary layer.

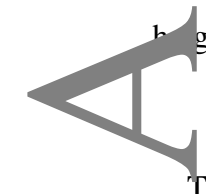

The magnitude of the turbulent mixing coefficient as computed in the numerical model (dashed lines in Figures $4 \mathrm{c}, \mathrm{d}$ and e) exhibits a parabolic shape along the vertical direction and is symmetric with respect to the middle of the MABL. The intensity of the vertical maximum of the mixing coefficient increases with SST.

As shown in Figure 3c, the MABL-averaged potential temperature from the numerical model (dashed line) follows SST (dotted line) with an horizontal lag. To represent the advection of the MABL thermodynamical structure (as discussed in Lambaerts et al. 2013) in the analytical model, the MABL potential temperature $\theta$ is set to have the same shape than the SST (17), but with $L=300 \mathrm{~km}$ and $x_{0}=2200 \mathrm{~km}$ (solid line). This profile follows closely the potential temperature obtained from the numerical model (dashed line), thus reproducing the numerically simulated pressure gradient. 
Following the fourth assumption of Section $2, K_{0}, K_{1}, K_{m}$ and $h$ are assumed to be linearly linked to potential temperature $\theta$ (in $\mathrm{K})$. To obtain the best match with the numerical results, this dependence is calibrated as

$$
\left\{\begin{array}{l}
K_{1}=K_{0}=10^{-5} \mathrm{~m}^{2} \mathrm{~s}^{-1} \\
K_{m}=1.5+3 \times \theta \mathrm{m}^{2} \mathrm{~s}^{-1} \\
h=134+142 \times \theta \mathrm{m}
\end{array}\right.
$$

\section{(1)}

the diffusion coefficient at the top and at the bottom of the MABL is of the order of magnitude of molecular viscosity, and its value in the middle increases linearly with potential temperature perturbation. As shown in Figures $4 \mathrm{c}$, $\mathrm{d}$ and e, the resulting mixing co fficient is of the order of magnitude of the one obtained in the numerical simulation. The extrapolated MABL height is consistent with the MABL height observed in numerical simulations before and after the front (see the dashed line in Figure 4a). Above the front, ras

the extrapolated value is higher than the value from numerical simulation, indicating that the link between $h$ and $\theta$ is no longer linear.

This can be attributed to non-linear advection effects in the heat equation solved by the numerical model.

Summarizing, the four assumptions made in the derivation of the analytical model are consistent with the numerical simulation. In ticular, Equation (18), is a strong result indicating that the turbulent structure of the MABL can be almost described as linearly related to the advected SST.

\subsection{Discussion (c. Section 5).}

sults of the numerical simulation and the analytical model are shown in Figures 3 and 4, for the total zonal and meridional wind re pectively. The evolution of the winds in the boundary layer is consistent with previous simulations (Spall 2007; Kilpatrick et al. 2014). In particular in both numerical and analytical models, a vertical shear is created over the cold water, stronger than above the warm water, where momentum mixing is enhanced due to thermal production of turbulent kinetic energy. As a result of the Coriolis for e, the shear occurs both in the zonal and meridional components of the wind. In both models, the zonal wind exhibits a sharp variation on top of the front, consistent with a dominant response of the wind divergence to the SST Laplacian in this configuration

The horizontal structure in both the analytical model and the numerical simulations can be split into three distinct regions. Vertical Ind profiles in each region are presented in Figure 5. Upwind and downwind of the front (respectively for $x \sim 200 \mathrm{~km}$, Figures 5a an $\mathrm{b}$ and for $x \sim 3000 \mathrm{~km}$, Figures $5 \mathrm{e}$ and $\mathrm{f}$ respectively), meridional and zonal wind shear is present. The shear is not constant on the vertical, but increases when approaching the top and bottom boundaries of the MABL, due to the parabolic shape of the mixing coefficient.

Focusing on the region upwind of the front, numerical simulations reveal the presence of a strongly stratified layer on top of the MABL (at around $150 \mathrm{~m}$ height, Figure 3a), that balances the sharp decrease of the ageostrophic wind to zero. The no-slip upper boundary condition enforced in the analytical model plays a similar role in developing a strong wind shear, even though it is located higher than in the numerical model (Figure 5a). However, a zone of supergeostrophic wind (at $z \sim 90 \mathrm{~m}$ in Figure 5a) is missed by the analytical model, possibly due to the presence of upper layer temperature stratification in the numerical model.

Above the SST front (between 1500 and $2500 \mathrm{~km}$ ), the effect of the pressure gradient on the momentum balance causes a horizontal wind divergence linked to the temperature Laplacian (Figure 3). Line plots (Figures 5c and d) further show that the main difference between the analytical and numerical model is in the meridional wind. The analytical model predicts a negative meridional wind (as can be seen also in Figure 4b). In this region, the pressure gradient induces a strong value of the non-dimensional number Pc, which implies the existence of a geostrophic meridional. wind overçming the.Ekman wind (see Section 3.2). The absence of this feature in This article is protected by copyright. All rights reserved. 
(a)

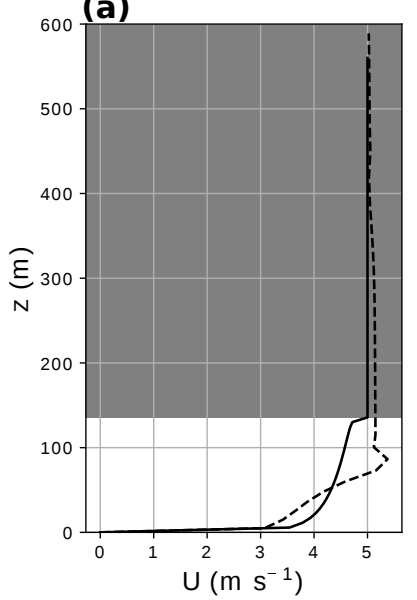

(b)

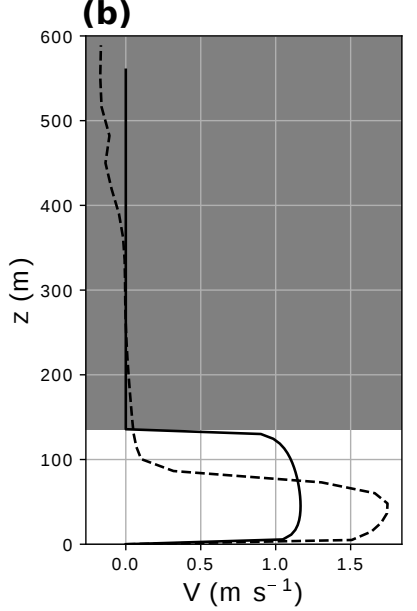

(c)

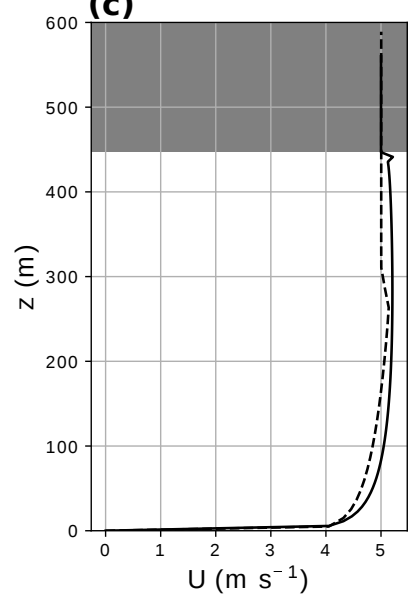

(d)

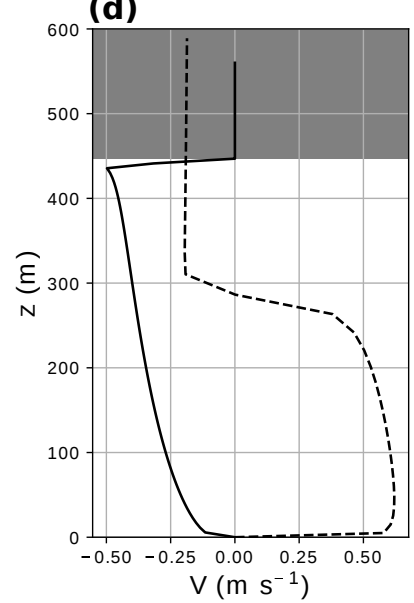

(e)

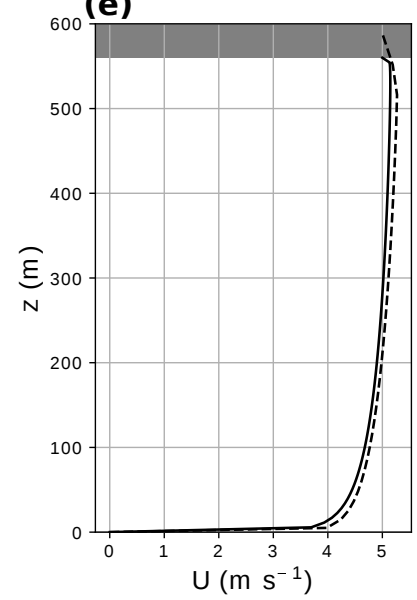

(f)

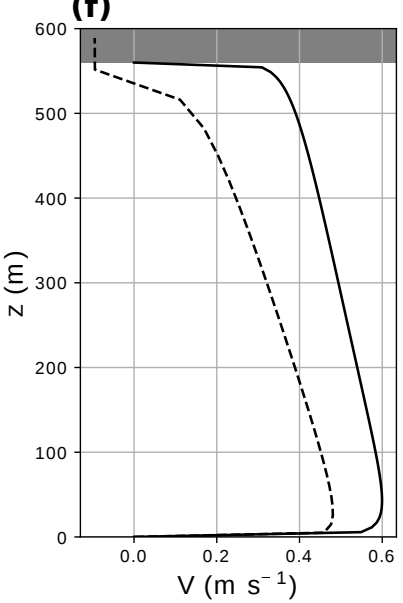

(1)

dure 5. Vertical profiles of total zonal [(a), (c), (e)] and meridional [(b), (d), (f)] winds from the analytical solution (solid line) and from the numerical model as simulated after 36 hours (dashed line): [(a), (b)] before the SST front, $x=200 \mathrm{~km}$; [(c), (d)] above the SST front, $x=2000 \mathrm{~km}$; [(e),(f)] after the SST front, $x=3000 \mathrm{~km}$. Grey lings denote heights above the extrapolated MABL height used in the analytical solution.

herical model results from the advection term. Thus, even though the Rossby number is weak in this particular configuration, ac ection still plays a role near the frontal region (as diagnosed in Kilpatrick et al. 2014, for stronger winds).

In all three regions, vertical profiles reveal that the main difference between the analytical and numerical model lies in the meridional ds. This indicates that the effect of advection is predominant for meridional winds, which are thus not well represented by the an alytical model. Note that this has no impact on the discussion on wind divergence in Section 5, since meridional winds have no eridional derivative in the present configuration (i.e. $\partial_{y} V=0$ ).

Equation (18) is a strong result of the analytical model indicating that the turbulent structure of the MABL can be linearly linked to SST. The sensitivity of the MABL structure to a change in this relation been studied and is not shown here. The internal structure of the MABL is not sensitive to a decrease in $K_{0}$ and $K_{1}$, whereas it diverges from the numerical solution when both these coefficients are increased.

Figure 6 shows the Ekman number as a function of the cross-front coordinate from the numerical simulation and the analytical model. Both values are similar upwind and downwind of the front. The numerical model shows an increase in Ekman number above the front (peaking at $x \sim 1800 \mathrm{~km}$ ) which is not present in the analytical model. The Ekman number increases with increasing $K_{e}$ and decreases with increasing $h$. Since, from Figure $4 \mathrm{~d}, K_{e}$ is lower in the numerical model than in the analytical solution in this region, the observed difference in Ekman number is due to a difference in $h$. Comparison of Figures 4a and b indeed shows that the MABL height in the numerical model is lower than the MABL height in the analytical model for $x \sim 1800$. This delayed increase in the numerical model MABL height is due to the non-linear.effect of advection on the heat budget, and results in a violation of the linear dependence 
between MABL height and potential temperature, as assumed in the analytical model. More generally, this indicates that advection intensity (which can vary depending on e.g. $U_{g}$ ) can be an environmental parameter affecting the Ekman number value, for a given SST front.

Figure 6 further shows that the Ekman number is lower in the downwind part of the front $(\mathrm{Ek} \sim 2)$ than in the upwind part $(\mathrm{Ek} \sim 6)$. This decrease is correlated with an increase of the zonal wind, and of the turbulent diffusion coefficient. Previous work (e.g. Frenger et al. 2013) attributed this wind increase to the downward momentum mixing mechanism, i.e. an enhanced downward transport of $\mathrm{m}$ mentum due to enhanced turbulence, leading to a stronger wind. What the present analysis shows is that this wind increase is related to a decrease in the Ekman number, i.e. to $\partial_{\theta} \mathrm{Ek}^{-1}$. The Ekman number is the ratio between the Ekman layer height $l_{e}$ and the MABL height $h$. This ratio can be interpreted as the relative efficiency of turbulence at mixing momentum $(K)$ with respect to its efficiency hixing heat (which contributes to setting the MABL height $h$ ). This analysis thus seems to indicate that the downward momentum miking mechanism could be not related to an increase in turbulent mixing but rather to a relative decrease of the turbulence mixing eff ciency on momentum with respect to its efficiency on heat.

To test the robustness of the above analysis, simulations were performed for a geostrophic wind of $15 \mathrm{~m} \mathrm{~s} \mathrm{~s}^{-1}$, in a similar configuration than in Kilpatrick et al. (2014) (see their Figure 2) and Spall (2007), i.e. where hypothesis (1) is no longer satisfied. The parameters of the model $\left(K_{0}, K_{1}, K_{m}\right.$ and $\left.h\right)$ were also linked linearly to potential temperature, which again followed SST with a horizontal lag. Zonal winds from the analytical model matched closely the numerical results, and differences were mainly observed for meridional winds. Those results indicate that (i) the horizontal lag in temperature variations accounts for most of the non-linear terms ecting the thermodynamical and the turbulent structure of the MABL for higher Rossby numbers; (ii) as observed for the $5 \mathrm{~m} \mathrm{~s}{ }^{-1}$ e, advection acts mostly on the meridional wind.
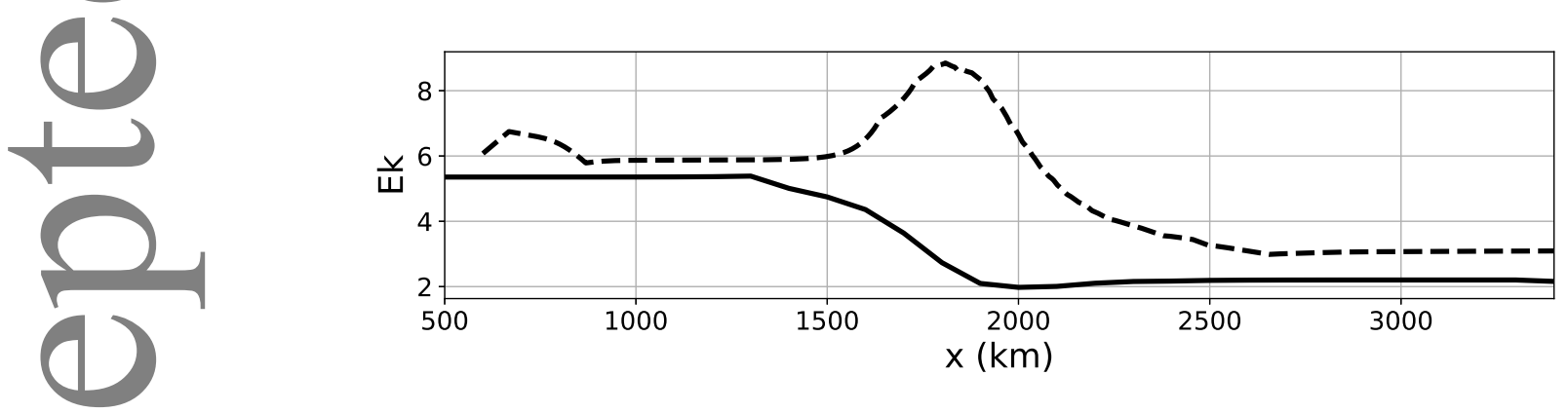

Figure 6. Ekman number from the analytical solution (solid line) and as simulated after 36 hours from the numerical model (dashed line).

\section{Horizontal wind divergence}

For weather and climate prediction, a key quantity arising from the MABL response to SST fronts is the average horizontal wind ivergence (e.g. Feliks et al. 2004; Minobe et al. 2008; Kilpatrick et al. 2014), defined as

$$
\boldsymbol{\nabla} \cdot \overline{\mathbf{U}}=\int_{0}^{h}\left(\partial_{x} \operatorname{Re} U+\partial_{y} \operatorname{Im} U\right) d z
$$

$\overline{\mathbf{U}}=\int_{0}^{h} \mathbf{U}$ the vertically-integrated wind. It is linked to the vertical velocity at the top of the MABL, which can influence the free troposphere above.

\subsection{Comparison with the numerical simulation}

The mean divergence from the analytical model (i.e. $\boldsymbol{\nabla} \cdot \overline{\mathbf{U}} / h$ ) is first compared to the numerical simulation (Figure 7). The numerical simulation exhibits a mean divergence proportional to the SST laplacian, with some horizontal lag (consistent with Lambaerts et al. 
2013). The pattern and amplitude of the divergence is well reproduced by the analytical solution, especially within the strong temperature gradient zone $(x \sim 2000 \mathrm{~km})$.

The analytical model exhibits however a stronger divergence upwind of the front. Comparison of Figure $3 \mathrm{a}$ and $\mathrm{b}$ reveals that the horizontal wind variation pattern causing the divergence is translated upwind in the analytical solution, i.e. it begins at $x \sim 1500 \mathrm{~km}$ instead of $x \sim 1800$ in the numerical model. This difference can thus be interpreted as a consequence of having neglected the nonlinear advection terms which, in the numerical model, affect the momentum budget, and also delay the response of the MABL height to emperature variations (through their effect on the heat budget).

Considering this overall good agreement between analytical and numerical solutions, the variation of wind divergence for different dynamical regimes is now investigated with the analytical solution.
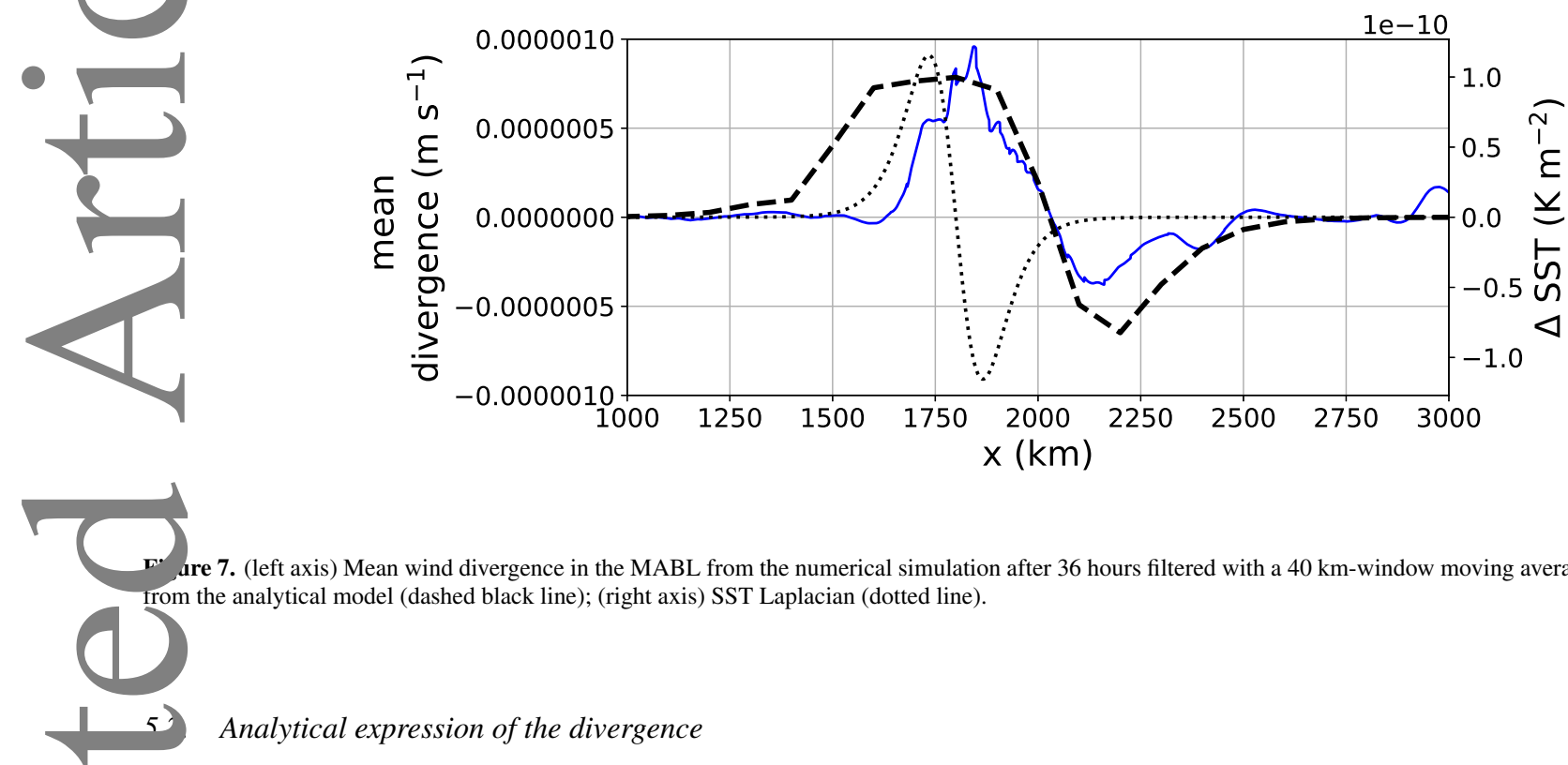

Thy simplest model for the horizontal wind divergence is described in Lindzen and Nigam (1987) and Minobe et al. (2008). In the present framework, it can be recovered by using a linear drag $\left(\partial_{z} \tau=-\epsilon U\right.$, with $\epsilon$ a proportionality coefficient) in Equation (10), ding

$$
\nabla \cdot \overline{\mathbf{U}}=\frac{\kappa \epsilon}{f^{2}+\epsilon^{2}} \nabla^{2} \theta
$$

with $\kappa=\left(g / \theta_{0}\right)\left(h^{2} / 2\right)$. As mentioned in the introduction, this simple relationship is a consequence of the pressure adjustment chanism, and links the wind divergence to the SST Laplacian (since $\theta$ was assumed to be roughly equal to SST in Section 2). est of the section, the analytical model with a parabolic diffusion coefficient is used to go beyond this formula.

We first consider a simplified case, where $f=0$, and the diffusion coefficient is maximum at the ground and nearly constant within the MABL. With these hypothesis, the wind divergence can be computed from the analytical solution of the model as (see Appendix B)

$$
\boldsymbol{\nabla} \cdot \overline{\mathbf{U}}=\frac{g h^{3} \theta \partial_{\theta} h}{\theta_{0}\left(K_{0}-K_{1}\right)} \nabla^{2} \theta-\frac{1}{2}\left(\mathbf{U}_{g} \cdot \nabla \theta\right) \partial_{\theta} h+\frac{g}{\theta_{0}} \frac{\partial}{\partial \theta}\left(\frac{h^{3} \theta \partial_{\theta} h}{K_{0}-K_{1}}\right)(\nabla \theta)^{2}
$$

Equation (21) contains three terms depending linearly on different functions of potential temperature. The first two terms relate the integrated wind divergence to the SST Laplacian and the downwind SST gradient. They can thus be related to the pressure adjustment mechanism and the downward momentum mixing mechanism respectively (even though we are considering here an integrated wind divergence and not the surface wind stress divergence). The third term is proportional to $(\nabla \theta)^{2}$, and is thus of the same sign than $\partial_{\theta}\left[\left(h^{3} \theta \partial_{\theta} h\right) /\left(K_{0}-K_{1}\right)\right]$. This dependence results from the assumption that $h$ and $K$ are only dependent on $\theta$ (the fourth assumption in Section 2), which implies that their spatial derivatives $\partial_{x}(\cdot)$ can be replaced by a temperature derivative $\partial_{x, y} \theta \partial_{\theta}(\cdot)$. If this assumption 
was relaxed, the third term would read

$$
\frac{\partial}{\partial x}\left(\frac{F(h)}{K_{0}-K_{1}}\right) \partial_{x} \theta+\frac{\partial}{\partial y}\left(\frac{F(h)}{K_{0}-K_{1}}\right) \partial_{y} \theta
$$

with $F(h)$ a function of the MABL height, i.e. it would be proportional to the SST gradient only.

The different terms in Equation (21) depend on the SST field, on $h, \theta, K$ and their derivatives with respect to SST. By denoting by $\Delta \theta$ the typical horizontal variation of SST such that $\nabla^{2} \theta$ varies as $\Delta \theta / L^{2}$ the first term in (21) varies as

$$
\frac{g h^{3} \theta \partial_{\theta} h}{\theta_{0}\left(K_{0}-K_{1}\right)} \nabla^{2} \theta \propto \frac{h^{2}}{K} \frac{h \Delta \theta}{L^{2}} \partial_{\theta} h
$$

Tl s scaling is the product of (i) $h^{2} / K$, a factor similar to the inverse of the Ekman number Ek ${ }^{-1}$ (Equation (11), even though in the present case $f=0$ ), i.e. related to the turbulent structure of the MABL and its adjustment to an SST front; (ii) $h \Delta \theta / L^{2}$ a factor related to the inverse relative scale of the SST front (i.e. for $f \neq 0$, to $\mathrm{Pc} / L$ ); (iii) $\partial_{\theta} h$, the variation of the MABL height with temperature, i.e. how it adjusts to SST-induced destabilisation. The product between $\mathrm{Ek}^{-1}$ and Pc (factors (i) and (ii) ) is the ratio between the pressure $\mathrm{n}$ and the turbulent mixing term in the momentum balance (10). Factor (iii) can be intepreted, in this simplified situation where $K \sim 0$, as being related to $\partial_{\theta} \mathrm{Ek}^{-1}$ (which is then $\partial_{\theta} h$ ) and thus to the intensity of the downward momentum mixing mechanism (see Section 4.3). This shows that this first term is related to the pressure adjustment mechanism (factors (i) and (ii), the relative importance of pressure in the MABL), but is a generalization of (20) since it is also modulated by the presence of the downward momentum mixing mechanism (by factor (iii)).

The second term in (21) is the product between $\partial_{\theta} h$, (i.e. the intensity of the downward momentum mixing) and the downwind tomperature gradient, scaling as $\Delta \theta / L$. The last term depends on how the pressure adjustment mechanism intensity (the first term) ies with temperature, i.e. related to the response of the MABL to SST variations.

The above analysis shows that each of the terms in the response of the integrated wind divergence can be factored into: a factor relted to the adjustment of the MABL to SST perturbations (i.e. to $\mathrm{Ek}^{-1}$ or $\partial_{\theta} \mathrm{Ek}^{-1}$ ), and a factor depending on the relative scale of the iront $L$. The scale-dependent factor indicates that the structure and causes of horizontal wind divergence change when different ho izontal scales are considered. In particular, the ratio between the Laplacian of temperature and the gradient of temperature varies as $L^{-1}$, with $L$ the typical length scale of the front. This has been shown in Skyllingstad et al. (2007) using a LES simulation of MABL. The Ekman number and its derivative, i.e. the adjustment of the MABL to a SST perturbation, could in principle vary de sending on e.g. SST, the upwind MABL, and the relative direction of the geostrophic wind with respect to the frontal gradient.

In the general case, the analytical model integrated divergence reads (see Appendix $\mathrm{C}$ for details):

$$
\boldsymbol{\nabla} \cdot \overline{\mathbf{U}}=\alpha_{L} \nabla^{2} \theta+\alpha_{D} \mathbf{U}_{g} \cdot \nabla \theta+\alpha_{G}(\nabla \theta)^{2}+\alpha_{C}\left(\mathbf{U}_{g} \times \nabla \theta\right)
$$

with coefficients defined in Equation (48), and representing the amplitude of the linear response of the wind divergence to different functions of potential temperature. The divergence contains the same terms as in the simple case described above, with an additional factor $\alpha_{C}$ representing the amplitude of the response to the cross-wind gradient. It is not discussed in the following, since the present model focuses on situations with a downwind SST gradient.

The analytical form of each of the coefficients introduced in (23) reveals that they are not dependent on the scale of the front $L$ or on $\Delta \theta$ (see Appendix C). All coefficients are also independent on the vertical structure of the MABL (not shown) as has been noted in Samelson et al. (2006), implying that they only depend on the average value of the mixing coefficient over the MABL $K_{e}$ and not on $K_{0}, K_{1}$ and $K_{m}$. For a given SST field, $K_{e}, \partial_{\theta} K_{e}, h$ and $\partial_{\theta} h$ are thus the free parameters determining the integrated wind divergence 
coefficients. We can thus reasonably assume that the same factorisation as for the simplified case (21) can be performed. i.e. that each of the terms in (23) contains a part depending only on $\mathrm{Ek}^{-1}$ and $\partial_{\theta} \mathrm{Ek}^{-1}$ and that the part depending on the relative scale of the front is fixed, depending solely on the derivatives of SST.

Figure 8 shows the dependence of the coefficients with Ek and $\partial_{\theta} \mathrm{Ek}$, varied by changing $K_{e}$ and $\partial_{\theta} K_{e}$ in the analytical model. Note first that $\alpha_{L}$ is independent of $\partial_{\theta} K$ (Figure 8b), and that it is dependent on $\partial_{\theta} h$ (not shown). Similarly, and increase of $\partial_{\theta} K_{e}$ causes an increase of the magnitude of $\alpha_{D}$ (Figure 8d). Both results are consistent with the simple case, (21). All three coefficients vanish with in feasing $K_{e}$ (Figures 8a, b and c), consistent with a decrease in wind shear discussed in Section 3.1. This implies that the imprint of an SST field on the integrated wind divergence decreases with increasing turbulence.

Figure 8a presents the variation of $\alpha_{L}$ with $K_{e}$. Two regimes are observed: an increase of $\alpha_{L}$, followed by a decrease when $K_{e}$ reases, the transition occurring for Ek of order unity. The Coriolis and the pressure forces dominate the momentum balance in the t regime. The increase of $\alpha_{L}$ with mixing is reminiscent of its increase with drag in the model of Equation (20). In the second re ime, the mixing and the pressure forces dominate and thus the pressure adjustment mechanism is diminished with increased mixing. Thpse regimes are absent in the simple model (21), and are thus a consequence of the parabolic vertical shape of the turbulent diffusion coefficient. A similar behaviour is observed when varying $\alpha_{G}$ with $\partial_{\theta} K_{e}$ (Figure 8f).

Variations of the different coefficients with the Ekman number and its derivative (i.e. the local adjustment of the MABL to SST prturbations) are essential for large scale applications. Glendening and Doyle (1995) studied the response of the MABL in terms of vertical wind to a meandering zonal SST front. They showed that it could vary depending on the bulk MABL adjustment (measured the deformation radius in their case) and the scale of the meander. If the present model is applied to a meandering configuration, n the local adjustment of the MABL could vary along the meander, which would translate into variations of Ek and $\partial_{\theta}$ Ek. The two re imes revealed by Figures $8 \mathrm{a}$ and $8 \mathrm{f}$ show that the resulting wind divergence (and thus vertical wind) response can be completely different depending on the bulk Ekman number value.

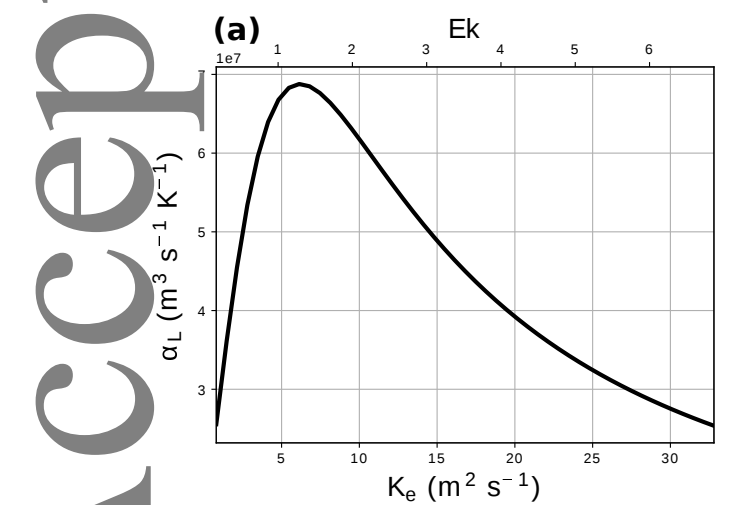

(b)

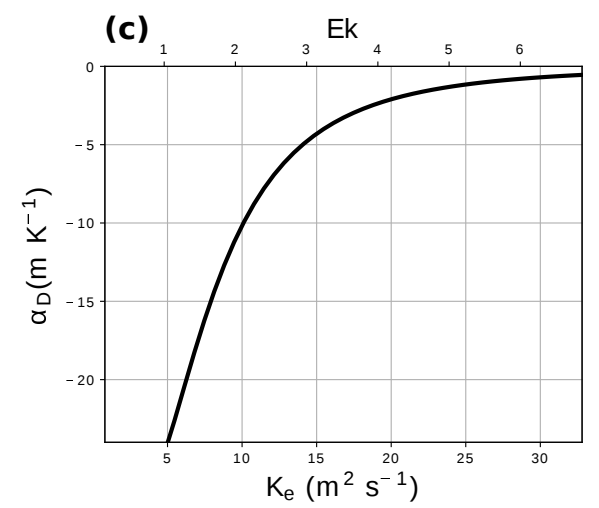

(d)

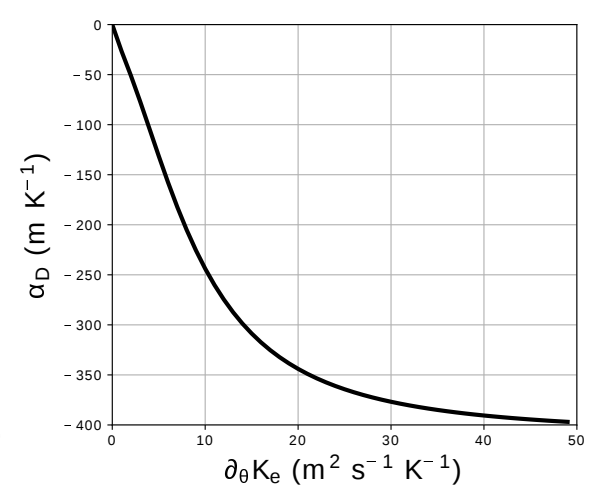

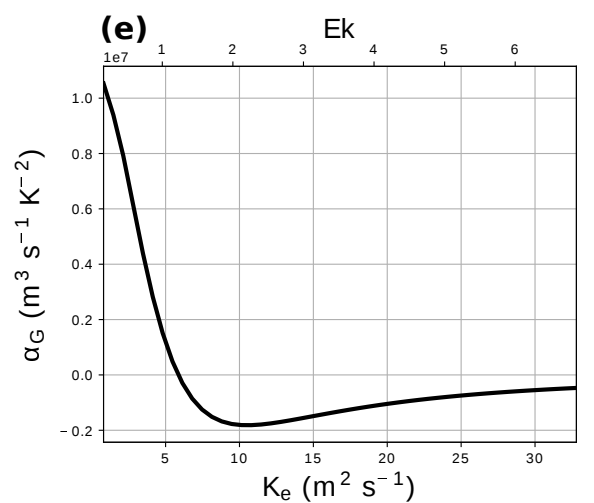

(f)

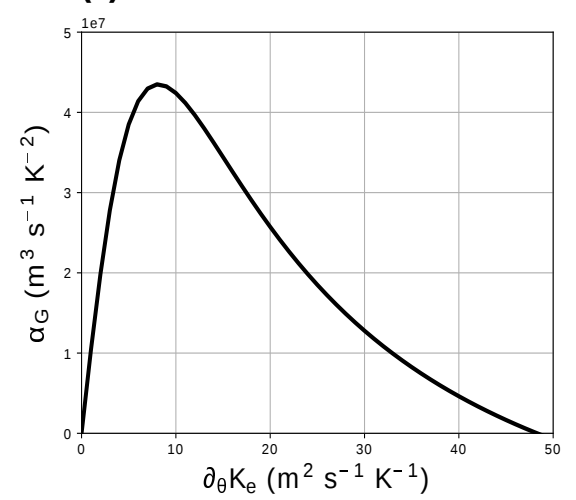

Figure 8. Variation of the coefficient linking horizontal wind divergence and [(a),(b)] temperature Laplacian $\left(\alpha_{L}\right)$; [(c),(d)] downwind temperature gradient $\left(\alpha_{D}\right)$; [(e), (f)] magnitude of the temperature gradient squared $\left(\alpha_{G}\right)$. The variation is as a function of [(a), (c), (e)] the mean diffusion coefficient in the MABL and [(b), (d), (f)] its temperature derivative.

This article is protected by copyright. All rights reserved. 


\subsection{Comparison with the literature}

The results of the analytical model are compared to three literature studies. First, the analytical model of Feliks et al. (2004), based on a similar equation than (10), with however a constant mixing coefficient $k_{0}=\left(h^{2} f\right) /\left(2 \pi^{2}\right)$ consistent with the standard Ekman layer theory. From equation (7) of their paper, if we let the MABL height vary with temperature, we get

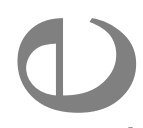

$$
\boldsymbol{\nabla} \cdot \overline{\mathbf{U}}=\frac{g h^{2}}{2 \pi f \theta_{0}}\left(1-\frac{1}{2 \pi}\right) \nabla^{2} \theta-\mathbf{U}_{g} \cdot \boldsymbol{\nabla} \theta \frac{\partial_{\theta} h}{\pi}+\frac{g h \partial_{\theta} h}{\pi f \theta_{0}}\left(1-\frac{1}{2 \pi}\right)(\boldsymbol{\nabla} \theta)^{2}+\left.\left(\mathbf{U}_{g} \times \nabla \theta\right)\right|_{z} \frac{\partial_{\theta} h}{\pi} .
$$

The coefficients of the response to the different derivatives of potential temperature vary quadratically or linearly with $h$, with no si $n$ of the different regimes as observed before. Indeed, in the model of Feliks et al. (2004), Ek being equal to 1 by definition, the Iransition cannot occur. Note that the cases of $E k \neq 1$ are not purely academic. As discussed in Section 3, these cases are found to be important to obtain a realistic internal structure of the MABL. No regimes are observed with variation of $\partial_{\theta} h$ (equivalent of $\partial_{\theta} K$ in the present model). This highlights again the qualitative difference between Equation (10) with a vertically-constant coefficient $K$ as osed to the non-constant case.

A second study (Lambaerts et al. 2013) evaluates the theoretical $\alpha_{L}$ coefficient of Feliks et al. (2004) (the first term in (24)) against a numerical simulation, for a configuration with $h=971 \mathrm{~m}$. The MABL is simulated on top of a SST field associated with a simulated turbulent mesoscale oceanic eddy field. The theoretical and numerical model values of $\alpha_{L}$ are respectively $11 \times 10^{6} \mathrm{~m}^{3} \mathrm{~s}^{-1} \mathrm{~K}^{-1}$ and $17 \times 10^{6} \mathrm{~m}^{3} \mathrm{~s}^{-1} \mathrm{~K}^{-1}$, for a divergence integrated until the middle of the MABL. Following the typical values used in Section 3, the ir numerical model value of $\alpha_{L}$ can be recovered using the present analytical model (48), assuming that $K_{e}=1.3 \mathrm{~m}^{2} \mathrm{~s}^{-1}$. This Corresponds to a specific $E k \sim 0.3$ regime. It highlights again the importance of the different regimes discussed above, Ek varying b ween 1 and 5 in the numerical simulations presented in Section 4.

Finally, the study of Plagge et al. (2016) used paired buoys to estimate the mean correlation coefficient between wind divergence d SST gradient for frontal scales of $\mathcal{O}(100) \mathrm{km}$. They found a value of $0.22 \mathrm{~m} \mathrm{~s}^{-1} \mathrm{~K}^{-1}$. This value also agrees with scatterometer ements (e.g. ONeill 2012). In the present model, this mean correlation coefficient is estimated as $\alpha_{D} U_{g} / h$. Assuming a MABL he ght of $500 \mathrm{~m}$ and values of $\partial_{\theta} K_{e}, \partial_{\theta} \delta$ and $K_{e}$ derived from the numerical simulation (18), results in $\alpha_{D} \sim 15 \mathrm{~m} \mathrm{~K} \mathrm{~K}^{-1}$. Further assuming an average geostrophic wind of $8 \mathrm{~m} \mathrm{~s}^{-1}$ results in a correlation coefficient of 0.27 , matching the value of Plagge $e t$ al. (2 16). Another commonly discussed quantity is the SST-surface wind stress correlation coefficient (e.g. Chelton et al. 2004). It is ent of the scope of the present model to discuss this quantity, which would require more realistic bottom boundary conditions (e.g. posing a boundary conditions on the momentum flux rather than on the wind).

\section{Conclusion}

We have presented an analytical model that describes the response of the MABL to an SST front in terms of ageostrophic wind. The model has been compared to a simple state-of-the-art numerical simulation. The assumptions underlying the model are valid for a cross-front geostrophic wind, blowing from the cold to the warm side of the front, and for a low Rossby number. However, the model is able to reproduce numerical simulations at higher Rossby numbers, except on top of the SST gradient, where advection is important. This results from the fact that the turbulent and thermodynamic structure of the analytical model are prescribed, and that non-linear effects affecting these structures can thus be partially accounted for.

Comparison between the analytical model and the numerical simulation highlighted the importance to consider a realistic turbulent diffusion coefficient (both its intensity and its vertical variation) to explain the vertical structure of the MABL. The ageostrophic wind in the MABL was explained by various dynamical balances depending an i.ts position relative to the SST front. These regimes 
were then characterised by non-dimensional numbers (in particular the Ekman number), and discussed within the framework of the analytical model. They revealed that the increase in zonal wind across the front, usually associated to the downward momentum mixing mechanism, could be linked to a decrease in the Ekman number. The effect of advection (not present in the analytical model) was shown to be important mainly for meridional winds, and on the MABL height above the front.

A closed-form expression for the integrated wind divergence in the MABL was also derived. This novel relation combines the effect of the downward momentum mixing mechanism and of the pressure adjustment mechanism, both already described in the literature. W hin the analytical model, both mechanisms have however an imprint on the wind divergence, linking it to multiple-order derivatives of SST, and not only to its Laplacian. The response to the SST derivatives was shown to depend on the dynamical regimes of the MABL, a feature which has never been discussed in the literature. Several realistic examples have been shown in which both of these imes are reached, showing their relevance. The existence of these regimes was shown to be a consequence of considering a realistic dif'usion coefficient in the analytical model.

The link of the wind divergence to multiple-order derivatives of SST is an important novel feature of the closed-form expression. It implies that the wind divergence response might change with the scale of the front. This should be investigated in future work, based on observations over sharp SST fronts (e.g. Chevallier et al. 2014). The sensitivity of the wind divergence to non-dimensional numbers characterising how the MABL turbulent structure adjusts to an SST perturbation is the second main result of this work. It implies that hortizontal gradients of vertical wind on top of the MABL might be sensitive to the turbulent properties of the MABL, which depend on environmental parameters. In its present form, the model could be used as a diagnostic tool to infer the internal structure of the IBL from the observed or simulated imprint of a SST field on the wind divergence. This could help characterizing the variability of response of the MABL to SST variations (e.g. the variability of the MABL height observed in Vihma et al. 1998; Hashizume et al. 202 ), which is essential for large scale applications.

\section{knowledgement}

Th. colde used to generate the figures is available freely on [link will be provided upon revision]. The authors thank the three at onymous reviewers and Pr. Marie-Noëlle Bouin for the insightful comments leading to significant improvements in the manuscript. ney also wish to thank Pr. Guillaume Lapeyre and Pr. Bertrand Chapron for the fruitful discussions. AA was supported by DGA grant N D0456JE075 and French Brittany Regional Council. The paper is a contribution to the COCOA project supported by the French National Research Agency (ANR) through contract ANR-16-CE01-0007.

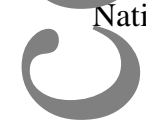

\section{Appendix A: General solution of the model}

In this Appendix we give some details on analytical solution of the model. Using the wind stress closure (7), the momentum equation (10) reads

$$
\partial_{z}\left(K(\theta, z) \partial_{z} U(\theta, z)\right)-i f U(\theta, z)=\frac{g}{\theta_{0}}\left(z-h_{e}\right)\left(\partial_{x} \theta+i \partial_{y} \theta\right)
$$

where we have defined an "effective" MABL height

$$
h_{e}=h(\theta)-\theta \partial_{\theta} h
$$

and where the turbulent diffusion coefficient is parabolic on the vertical 
Note that having a realistic concave mixing coefficient in the vertical direction requires that $C$ is negative.

This equation is solved for the ageostrophic wind $U$ by using the method of undetermined coefficients: the solution is found as a superposition of a particular solution to (25), $U_{p}$, and a solution to the homogeneous problem, $U_{h}$.

A particular solution to (10) is a first degree polynomial, which reads

$$
U_{p}(z)=\frac{g}{\theta_{0}}\left(\partial_{x} \theta+i \partial_{y} \theta\right)\left[\frac{h_{e}}{i f}-\frac{z}{i f-2 C}+\frac{C h-B}{i f(i f-2 C)}\right],
$$

\section{assuming that $f \neq 0$.}

The homogeneous equation of (25) (i.e. whitout the right hand side) can be rewritten as a Legendre differential equation

$$
\left(1-Z^{2}\right) \frac{d^{2} U(Z)}{d Z^{2}}-2 Z \frac{d U(Z)}{d Z}+\lambda(\lambda+1) U(Z)=0
$$

by using the change of variable

$$
\begin{gathered}
Z(z)=\frac{1}{\left(B^{2}-4 A C\right)^{1 / 2}}\left[2 C\left(z-\frac{h}{2}\right)+B\right], \\
\lambda=\frac{1}{2}\left(\sqrt{\frac{4 i f}{C}+1}-1\right) .
\end{gathered}
$$

solution of this equation is

$$
U_{h}(z)=c_{1} P_{\lambda}[Z(z)]+c_{2} Q_{\lambda}[Z(z)]
$$

ere $P_{\lambda}(Z)$ and $Q_{\lambda}(Z)$ are the Legendre functions of degree $\lambda$ (and of order zero), of the first and second kind respectively oramowitz and Stegun 1964). Note that the Legendre functions are defined for $Z$ between minus one and one, which is the case II he roots of $K$ are above and below the MABL. This is necessary for physical consistency.

me coefficients $c_{1}$ and $c_{2}$ are determined by using the boundary conditions (6) and read

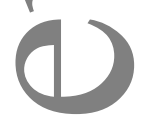

.

$$
\left\{\begin{array}{l}
c_{1}=D\left\{Q_{\lambda}[Z(h)]\left[U_{p}(0)+U_{g}\right]-Q_{\lambda}[Z(0)] U_{p}(h)\right\} \\
c_{2}=-D\left\{P_{\lambda}[Z(h)]\left[U_{p}(0)+U_{g}\right]-P_{\lambda}[Z(0)] U_{p}(h)\right\}
\end{array},\right.
$$

(

$$
D=\left\{P_{\lambda}[Z(h)] Q_{\lambda}[Z(0)]-Q_{\lambda}[Z(h)] P_{\lambda}[Z(0)]\right\}^{-1}
$$

Finally, the total solution to (25) reads

$$
U(\theta, z)=U_{p}(\theta, z)+\left[U_{p}(\theta, 0)+U_{g}\right] H_{h}(\theta, z)-U_{p}(\theta, h) H_{0}(\theta, z)
$$

with

$$
\left\{\begin{array}{l}
H_{h}(z)=D\left\{P_{\lambda}[Z(z)] Q_{\lambda}[Z(h)]-Q_{\lambda}[Z(z)] P_{\lambda}[Z(h)]\right\} \\
H_{0}(z)=D\left\{P_{\lambda}[Z(z)] Q_{\lambda}[Z(0)]-Q_{\lambda}[Z(z)] P_{\lambda}[Z(0)]\right\}
\end{array}\right.
$$

The particular solution $U_{p}$, defined in Equation (28), depends on the magnitude of the pressure force and the turbulent diffusion coefficient structure. However, the functions $H_{0}$ and $H_{h}$ rely solely on an Ekman balance between turbulent dissipation and Coriolis force, since they result from the solution of the homogeneous problem (yhitout the pressure force). In particular $H_{h}$ defines a 
Using the expression of $c_{1}$ and $c_{2}$ from (33), the height-integrated complex ageostrophic wind reads

$$
\bar{U}=\frac{g}{2 C \theta_{0}}\left(\partial_{x} \theta+i \partial_{y} \theta\right)\left\{\frac{3 h^{2}}{2}+2 \theta h \partial_{\theta} h+H(h / r)\right\}
$$

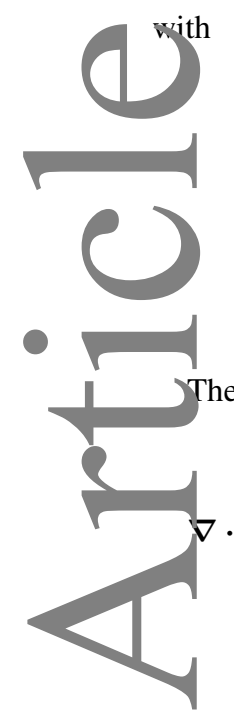

$$
\left\{\begin{array}{l}
F(x)=h_{e} \ln \left(1-x^{2}\right)-h \\
G(x)=\frac{\ln \left(1-x^{2}\right)}{2 Q_{0}(x)} \\
H(x)=r F(x) G(x)-2 r h_{e} Q_{0}(x)
\end{array}\right.
$$

$$
+\left(\mathbf{U}_{g} \cdot \nabla \theta\right) \partial_{\theta}[r G(h / r)]
$$

The assumption that the turbulent coefficient is nearly constant on the vertical implies that its positive root is located much higher th $h$ the MABL height, i.e. $h / r \ll 1$. Within this limit

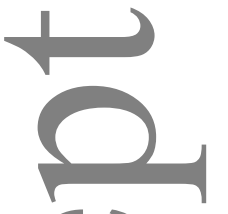

$$
\left\{\begin{array}{l}
G(x)=-\frac{x}{2}-\frac{x^{3}}{12}+\mathcal{O}\left(x^{5}\right) \\
H(x)=-r h\left[\frac{3+4 \theta \partial_{\theta} \ln h}{2} x+\frac{1+2 \theta \partial_{\theta} \ln h}{12} x^{3}+\mathcal{O}\left(x^{5}\right)\right]
\end{array}\right.
$$

placing these expressions in (45) leads to (21).

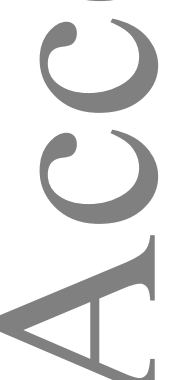

Appendix C: General form of wind divergence

The wind divergence is obtained by defining $\Pi_{r}$ and $\Pi_{i}$ as

$$
U_{p}(z)=\left(\partial_{x} \theta+i \partial_{y} \theta\right)\left(\Pi_{r}+i \Pi_{i}\right)
$$

i.e. separating the dependence in the gradient of potential temperature from the dependence in MABL height and vertical wind shear

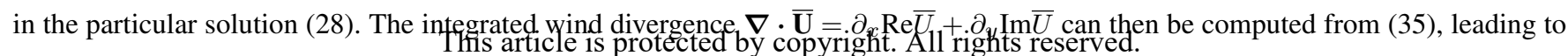


Equation (23), with

$$
\left\{\begin{aligned}
\alpha_{L} & =\int_{0}^{h}\left[\Pi_{r}(z)+\Pi_{r}(0) \operatorname{Re} H_{h}(z)-\Pi_{i}(0) \operatorname{Im} H_{h}(z)\right. \\
& \left.-\Pi_{r}(h) \operatorname{Re} H_{0}(z)+\Pi_{i}(h) \operatorname{Im} H_{0}(z)\right] d z \\
\alpha_{G} & =\int_{0}^{h} \partial_{\theta}\left[\Pi_{r}(z)+\Pi_{r}(0) \operatorname{Re} H_{h}(z)-\Pi_{i}(0) \operatorname{Im} H_{h}(z)\right. \\
& \left.-\Pi_{r}(h) \operatorname{Re} H_{0}(z)+\Pi_{i}(h) \operatorname{Im} H_{0}(z)\right] d z \\
\alpha_{D} & =\int_{0}^{h} \partial_{\theta}\left[\operatorname{Re} H_{h}(z)\right] d z \\
\alpha_{C} & =-\int_{0}^{h} \partial_{\theta}\left[\operatorname{Im} H_{h}(z)\right] d z
\end{aligned}\right.
$$

four coefficients contain no quantities related to the temperature derivatives: $H_{0}$ and $H_{h}$ result from the solution to the

nogeneous problem (i.e. the momentum equation without the pressure term), and $\Pi_{r}$ and $\Pi_{i}$ were defined above as the components he particular solution without the effects of the temperature gradient.

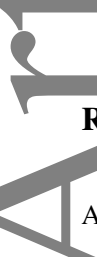

\section{References}

Abramowitz M, Stegun IA. 1964. Handbook of mathematical functions, vol. 55. Courier Corporation.

Al lerson SP. 2001. On the atmospheric boundary layer over the equatorial front. Journal of climate 14(7): 1688-1695, doi:10.1175/1520-0442(2001)014〈1688: OTABLO $>2.0 . \mathrm{CO} ; 2$.

geault P, Lacarrere P. 1989. Parameterization of orography-induced turbulence in a mesobeta-scale model. Mon. Wea. Rev. 117: 1872-1890, doi: 0.1175/1520-0493(1989)117〈1872:pooiti $\rangle 2.0 . c o ; 2$.

Dourras D, Reverdin G, Giordani H, Caniaux G. 2004. Response of the atmospheric boundary layer to a mesoscale oceanic eddy in the northeast atlantic. $J$. Geophys. Res.: Atmos. 109, doi:10.1029/2004JD004799.

Br wn R, Liu WT. 1982. An operational large-scale marine planetary boundary layer model. Journal of Applied Meteorology 21(3): 261-269, doi: 10.1175/1520-0450(1982)021<0261:AOLSMP $\rangle 2.0 . C O ; 2$.

Businger JA, Shaw WJ. 1984. The response of the marine boundary layer to mesoscale variations in sea-surface temperature. Dynam. Atmos. Ocean 8: 267-281, doi:10.1016/0377-0265(84)90012-5.

Ch Iton DB, Schlax MG, Freilich MH, Milliff RF. 2004. Satellite measurements reveal persistent small-scale features in ocean winds. Science 303: 978-983, doi: $10.1126 /$ science. 1091901 .

$\mathrm{Cl}$

lton DB, Schlax MG, Samelson RM. 2007. Summertime coupling between sea surface temperature and wind stress in the California current System. J. Phys. Oceanogr. 37: 495-517, doi:10.1175/JPO3025.1.

Ch Iton DB, Xie SP. 2010. Coupled ocean-atmosphere interaction at oceanic mesoscales. Oceanography 23: 52-69, doi:10.5670/oceanog.2010.05.

Chevallier C, Herbette S, Marié L, Le Borgne P, Marsouin A, Péré S, Levier B, Reason C. 2014. Observations of the ushant front displacements with msg/seviri (erived sea surface temperature data. Remote sensing of environment 146: 3-10, doi:10.1016/j.rse.2013.07.038

Cuxart J, Bougeault P, Redelsperger JL. 2000. A turbulence scheme allowing for mesoscale and large-eddy simulations. Quart. J. Roy. Meteor. Soc. 126: 1-30, coi:10.1002/qj.49712656202.

Fairall C, Bradley EF, Hare J, Grachev A, Edson J. 2003. Bulk parameterization of air-sea fluxes: updates and verification for the coare algorithm. J. Climate 16: 571-591, doi:10.1175/1520-0442(2003)016〈0571:bpoasf $\rangle 2.0 . c 0 ; 2$.

Feliks Y, Ghil M, Simonnet E. 2004. Low-frequency variability in the midlatitude atmosphere induced by an oceanic thermal front. J. Atmos. Sci. 61: 961-981, doi:10.1175/jas3780.1.

Foussard A, Lapeyre G, Plougonven R. 2018. Storm tracks response to oceanic eddies in idealized atmospheric simulations. Journal of Climate (2018), doi: 10.1175/JCLI-D-18-0415.1.

Foussard A, Lapeyre G, Plougonven R. 2019. Storm track response to oceanic eddies in idealized atmospheric simulations. Journal of Climate 32(2): 445-463, doi:10.1175/JCLI-D-18-0415.1.

Frenger I, Gruber N, Knutti R, Münnich M. 2013. Imprint of southern ocean eddies on winds, clouds and rainfall. Nature geoscience 6(8): 608, doi: $10.1038 /$ ngeo 1863 .

This article is protected by copyright. All rights reserved. 
Glendening JW, Doyle JD. 1995. Mesoscale response to a meandering surface temperature interface. Journal of the atmospheric sciences 52(5): 505-518, doi:10.1175/1520-0469(1995)052<0505:MRTAMS $\rangle 2.0 . C O ; 2$.

Hashizume H, Xie SP, Fujiwara M, Shiotani M, Watanabe T, Tanimoto Y, Liu WT, Takeuchi K. 2002. Direct observations of atmospheric boundary layer response to sst variations associated with tropical instability waves over the eastern equatorial pacific. Journal of Climate 15(23): 3379-3393, doi: 10.1175/1520-0442(2002)015〈3379:DOOABL $\rangle 2.0 . C O ; 2$.

Hayes SP, McPhaden MJ, Wallace JM. 1989. The influence of sea-surface temperature on surface wind in the eastern equatorial pacific: weekly to monthly variability. J. Climate 2: 1500-1506, doi:10.1175/1520-0442(1989)002〈1500:TIOSST $\rangle$ 2.0.CO;2.

Hs S, Fett R, La Violette PE. 1985. Variations in atmospheric mixing height across oceanic thermal fronts. J. Geophys. Res.: Oceans 90: 3211-3224, doi: 10.1029/jc090ic02p03211.

Hst SA. 1984. Sea-breeze-like winds across the north wall of the gulf stream: An analytical model. J. Geophys. Res.: Oceans 89: 2025-2028, doi: 10.1029/JC089iC02p02025.

wai Y, Tomita H, Cronin MF, Bond NA. 2014. Atmospheric pressure response to mesoscale sea surface temperature variations in the kuroshio extension egion: In situ evidence. Journal of Geophysical Research: Atmospheres 119(13): 8015-8031, doi:doi/pdf/10.1002/2013JD021126.

Ki atrick T, Schneider N, Qiu B. 2014. Boundary layer convergence induced by strong winds across a midlatitude SST front. J. Climate 27: 1698-1718, doi:10.1175/JCLI-D-13-00101.1.

Kulryavtsev V. 1996. A simplified model for the transformation of the atmospheric planetary boundary layer overlying a thermal front in the sea. Physical ceanography 7(2): 99, doi:10.1007/BF02509814.

Lac C, Chaboureau JP, Masson V, et al. 2018. Overview of the Meso-NH model version 5.4 and its applications . Geoscientific Model Development 1: 1929-1969, oi:10.5194/gmd-72811-1929-2018.

Lafore JP, Stein J, Asencio N, Bougeault P, Ducrocq V, Duron J, Fischer C, Héreil P, Mascart P, Masson V, Pinty JP, Redelsperger JL, Richard E, VilàGuerau de Arellano J. 1998. The Meso-NH atmospheric simulation system. Part I: adiabatic formulation and control simulations. Ann. Geophys. 16: 90-109, oi:10.1007/s00585-997-0090-6

Laikhtman D, Yordanov D. 1979. On the vertical velocity at the top of the planetary boundary layer in nonstationary conditions. Boundary-Layer Meteorology 7(3): 293-296, doi:10.1007/BF00117920.

La nbaerts J, Lapeyre G, Plougonven R, Klein P. 2013. Atmospheric response to sea surface temperature mesoscale structures. J. Geophys. Res.: Atmos. 118: 9611-9621, doi:10.1002/jgrd.50769.

Lin lzen RS, Nigam S. 1987. On the role of sea surface temperature gradients in forcing low-level winds and convergence in the tropics. J. Atmos. Sci. 44: L418†2436, doi:10.1175/1520-0469(1987)044〈2418:OTROSS $\rangle 2.0 . C O ; 2$.

Li TW, Xie X, Polito PS, Xie SP, Hashizume H. 2000. Atmospheric manifestation of tropical instability wave observed by quikscat and tropical rain measuring mission. Geophys. Res. Lett. 27: 2545-2548, doi:10.1029/2000g1011545.

M obe S, Kuwano-Yoshida A, Komori N, Xie SP, Small RJ. 2008. Influence of the gulf stream on the troposphere. Nature 452: 206-209, doi:10.1038/ nature 06690

M) k WH. 1950. On the wind-driven ocean circulation. Journal of meteorology 7(2): 80-93, doi:10.1175/1520-0469(1950)007〈0080:OTWDOC $>2.0 . C O ; 2$.

U'Neill LW, Chelton DB, Esbensen SK. 2003. Observations of SST-induced perturbations of the wind stress field over the southern ocean on seasonal timescales. Climate 16: 2340-2354, doi:10.1175/2780.1.

O’Neill LW, Chelton DB, Esbensen SK, Wentz FJ. 2005. High-resolution satellite measurements of the atmospheric boundary layer response to SST variations long the Agulhas return current. J. Climate 18: 2706-2723, doi:10.1175/JCLI3415.1.

ONeill LW. 2012. Wind speed and stability effects on coupling between surface wind stress and sst observed from buoys and satellite. Journal of Climate 25(5): 1544-1569, doi:10.1175/JCLI-D-11-00121.1.

ONeill LW, Haack T, Chelton DB, Skyllingstad E. 2017. The gulf stream convergence zone in the time-mean winds. Journal of the Atmospheric Sciences 74(7): 2383-2412, doi:10.1175/JAS-D-16-0213.1

Perlin N, De Szoeke SP, Chelton DB, Samelson RM, Skyllingstad ED, ONeill LW. 2014. Modeling the atmospheric boundary layer wind response to mesoscale sea surface temperature perturbations. Monthly Weather Review 142(11): 4284-4307, doi:10.1175/MWR-D-13-00332.1.

Piazza M, Terray L, Boé J, Maisonnave E, Sanchez-Gomez E. 2016. Influence of small-scale north atlantic sea surface temperature patterns on the marine boundary layer and free troposphere: A study using the atmospheric arpege model. Climate dynamics 46(5-6): 1699-1717, doi:10.1007/s00382-015-2669-z.

Plagge A, Edson JB, Vandemark D. 2016. In situ and satellite evaluation of air-sea flux variation near ocean temperature gradients. Journal of Climate 29(4): 1583-1602, doi:10.1175/JCLI-D-15-0489.1.

This article is protected by copyright. All rights reserved. 
Plougonven R, Foussard A, Lapeyre G. 2018. Comments on the gulf stream convergence zone in the time-mean winds. Journal of the Atmospheric Sciences 75(6): 2139-2149, doi:10.1175/JAS-D-17-0369.1.

Samelson R, Skyllingstad E, Chelton D, Esbensen S, O’Neill L, Thum N. 2006. On the coupling of wind stress and sea surface temperature. J. Climate 19: 1557-1566, doi:10.1175/JCLI3682.1.

Schneider N, Qiu B. 2015. The atmospheric response to weak sea surface temperature fronts. J. Atmos. Sci. 72: 3356-3377, doi:jas-d-14-0212.1.

Skyllingstad ED, Vickers D, Mahrt L, Samelson R. 2007. Effects of mesoscale sea-surface temperature fronts on the marine atmospheric boundary layer. Boundary-layer meteorology 123(2): 219-237, doi:10.1007/s10546-006-9127-8.

Sn 11 R, Xie S, ONeill L, Seo H, Song Q, Cornillon P, Spall M, Minobe S, et al. 2008. Air-sea interaction over ocean fronts and eddies. Dynam. Atmos. Ocean 45: 274-319, doi:10.1016/j.dynatmoce.2008.01.001.

Spall MA. 2007. Midlatitude wind stress-sea surface temperature coupling in the vicinity of oceanic fronts. J. Climate 20: 3785-3801, doi:10.1175/JCLI4234.1.

Ta atama K, Minobe S, Inatsu M, Small RJ. 2012. Diagnostics for near-surface wind convergence/divergence response to the gulf stream in a regional atmospheric model. Atmospheric Science Letters 13(1): 16-21, doi:10.1002/asl.355.

ranatama K, Minobe S, Inatsu M, Small RJ. 2015. Diagnostics for near-surface wind response to the gulf stream in a regional atmospheric model. Journal of Slimate 28(1): 238-255, doi:10.1175/JCLI-D-13-00668.1.

Vihma T, Uotila J, Launiainen J. 1998. Air-sea interaction over a thermal marine front in the denmark strait. Journal of Geophysical Research: Oceans 103(C12): 2,7665-27 678, doi:10.1029/98JC02415.

lace JM, Mitchell TP, Deser C. 1989. The influence of sea-surface temperature on surface wind in the eastern equatorial pacific: seasonal and interannual variability. J. Climate 2: 1492-1499, doi:10.1175/1520-0442(1989)002〈1492:TIOSST $\rangle 2.0 . C O ; 2$.

SP. 2004. Satellite observations of cool oceanatmosphere interaction. Bull. Amer. Meteor. Soc. 85: 195-208, doi:10.1175/BAMS-85-2-195.

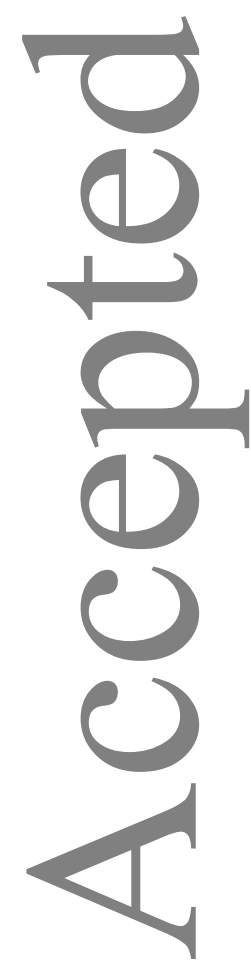

This article is protected by copyright. All rights reserved. 
